\title{
A Model of Intracellular Theta Phase Precession Dependent on Intrinsic Subthreshold Membrane Currents
}

\author{
L. Stan Leung \\ Department of Physiology and Pharmacology, University of Western Ontario, London, Ontario N6A5C1, Canada
}

\begin{abstract}
A hippocampal place cell fires at an increasingly earlier phase in relation to the extracellular theta rhythm as a rodent moves through the place field. The present report presents a compartment model of a CA1 pyramidal cell that explains the increase in amplitude and the phase precession of intracellular theta oscillations, with the assumption that the cell receives an asymmetric ramp depolarization $(<10$ $\mathrm{mV}$ ) in the place field and rhythmic inhibitory and/or excitatory synaptic driving. Intracellular subthreshold membrane potential oscillations (MPOs) increase in amplitude and frequency, and show phase precession within the place field. Theta phase precession and MPO power and frequency increase in the place field are caused by a shift in excitatory-inhibitory response, intrinsic theta-frequency resonance, and intrinsic oscillations that depend on voltage-dependent persistent $\mathrm{Na}^{+}$and slowly inactivating $\mathrm{K}^{+}$currents, but not on $I_{\mathrm{h}}$. Phase precession is diminished when theta-frequency resonance is decreased. Simulated spikes fire near the peak of MPOs and precess similarly as the MPOs. The phase of the MPOs/spikes codes for distance in a one-dimensional place field, and phase precession is only weakly dependent on firing rate, running speed, or the duration needed to cross the place field. In addition, phase precession within the place field resumes quickly after disruption by maximal afferent pulse stimulation.
\end{abstract}

\section{Introduction}

A place cell fires at a high rate when an animal runs through a particular location in the environment (O'Keefe and Nadel, 1978; Muller, 1996), with action potentials occurring progressively earlier in the theta-frequency cycle (O'Keefe and Recce, 1993; Skaggs et al., 1996). Theta $(4-10 \mathrm{~Hz})$ rhythm in the hippocampus and related structures (Vanderwolf, 1988; Stewart and Fox, 1990; Bland and Colom, 1993; Buzsáki, 2002) serves as a reference for a phase code (Hopfield, 1995) of an animal's location at different running velocities (Huxter et al., 2003).

Harvey et al. (2009) showed three main "subthreshold signatures" of place cells by whole-cell recording of hippocampal neurons in head-fixed mice running through a virtual reality track: (1) an asymmetric ramp-like depolarization, (2) an increase in the amplitude of intracellular theta oscillations, and (3) a phase precession of the peaks of the membrane potential oscillations (MPOs) with the extracellularly recorded theta rhythm. Since spikes fire near the peak of the MPOs (Harvey et al., 2009), spike precession in the place field is determined by MPO precession. Furthermore, the increase in amplitude of the MPOs constrains the participation of the rhythmic EPSPs in intracellular theta generation, since rhythmic EPSPs decrease with depolarization

\footnotetext{
Received Feb. 2, 2011; revised June 29, 2011; accepted July 7, 2011.

Author contributions: L.S.L. designed research; L.S.L. performed research; L.S.L. analyzed data; L.S.L. wrote the paper.

This work was supported by Canadian Institutes of Health Research Grant 15685 and the Natural Sciences and Engineering Research Council of Canada. I thank Gyuri Buzsáki, Brian Bland, and Min-Ching Kuo for comments on this study, and Terrence Sejnowski for providing a stimulating environment for starting the simulations.

Correspondence should be addressed to Dr. L. Stan Leung, Department of Physiology and Pharmacology, University of Western Ontario, London, 0N N6A5C1, Canada. E-mail: sleung@uwo.ca.

DOI:10.1523/JNEUROSCI.0586-11.2011

Copyright $\odot 2011$ the authors $\quad 0270-6474 / 11 / 3112282-15 \$ 15.00 / 0$
}

while rhythmic IPSPs increase (Leung and Yim, 1986; Fox, 1989; Ylinen et al., 1995; Bland et al., 2002).

Various models have been proposed for phase precession of place cell firing. Linear interference models propose MPOs of higher frequency at the dendrites compared with the soma (Burgess and O'Keefe, 1996; Lengyel et al., 2003). Other models are not explicit as to the increase in MPO frequency but propose that increasing dendritic excitation over somatic inhibition fires somatic spikes earlier in each theta cycle (Kamondi et al., 1998; Magee, 2001; Harris et al., 2002; Losonczy et al., 2010). In addition, a slow ramp-like depolarization would decrease the latency of spike onset (Harris et al., 2002; Mehta et al., 2002; McLelland and Paulsen, 2009). Some models emphasize that a neural network is critical for phase precession (Jensen and Lisman, 1996; Tsodyks et al., 1996; Wallenstein and Hasselmo, 1997; Bose and Recce, 2001; Hasselmo and Eichenbaum, 2005; Geisler et al., $2007,2010)$, but few models address fully the intrinsic properties of single neurons.

Intrinsic theta-frequency MPOs were induced by a small depolarization in entorhinal cortex stellate cells (Alonso and Llinás, 1989) and hippocampal CA1/CA3 pyramidal cells (Leung and Yim, 1991). In hippocampal pyramidal cells, a persistent $\mathrm{Na}^{+}$ current $I_{\mathrm{NaP}}$ and a slowly inactivating $\mathrm{K}^{+}$current $I_{\mathrm{KS}}$ or $I_{\mathrm{M}}$ are required for generating low-threshold MPOs (Leung and Yim, 1991) and somatic resonance at theta frequency (Leung and $\mathrm{Yu}$, 1998; Hu et al., 2002, 2007, 2009).

In the present report, electrophysiological responses of a CA1 pyramidal cell are simulated by a compartment model with $I_{\mathrm{NaP}}$ and $I_{\mathrm{KS}}$, in addition to other intrinsic currents. When a depolarization ramp and rhythmic synaptic driving are assumed, the model shows phase precession, and frequency and amplitude increase of the subthreshold MPOs. 


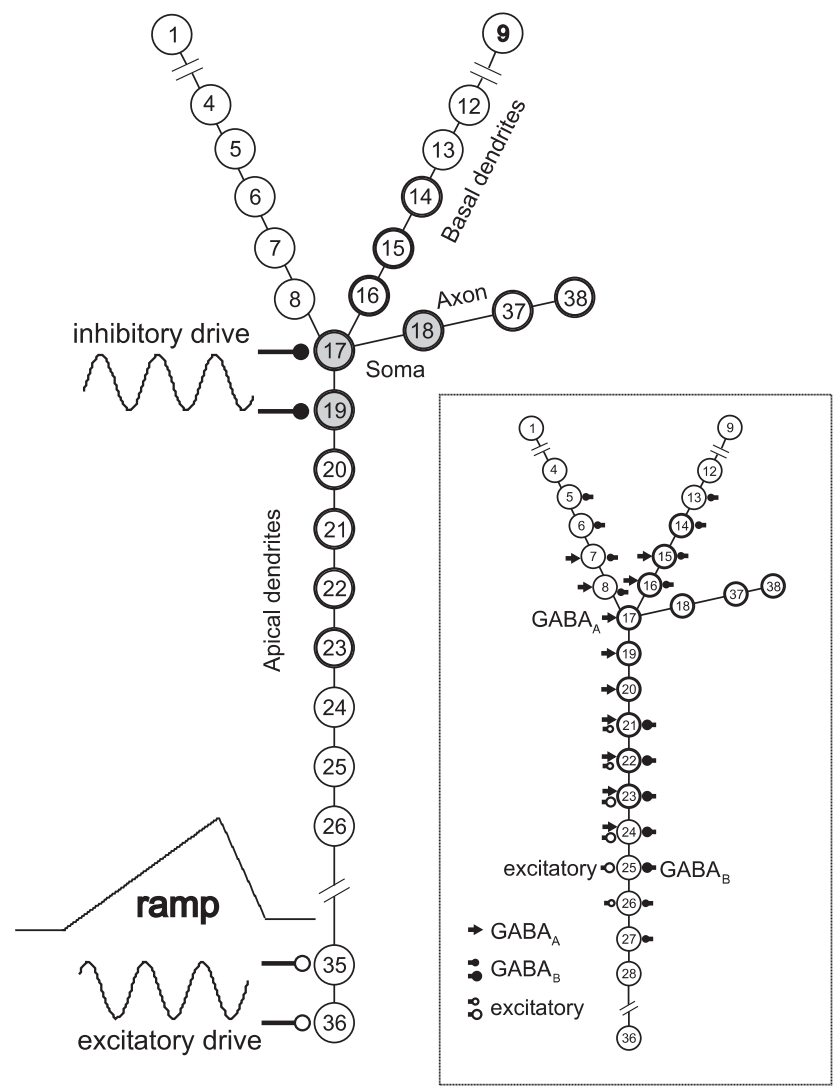

Figure 1. Model of CA1 pyramidal cell consists of 38 compartments representing different parts of the cell. An axon [compartment (C) 18, 37, 38], two basal dendritic branches (C1-8, $(9-16)$, and an apical dendritic branch (C19-36) representing the combined apical dendritic tree, originate from the soma (C17). Persistent $\mathrm{Na}^{+}$and slow $\mathrm{K}^{+}$-inactivating currents are assumed only at the proximal compartments (C17-19; $\mathrm{Col}-$ ored gray), while thick circles indicate the excitable compartments with $\mathrm{Na}^{+}$action potential current and $I_{K}$. The dendrites have $I_{h}, I_{A}$ conductance that increase distally. For the present simulations, sinusoidal inhibitory currents (assumed to start at phase $0^{\circ}$ ) drive proximal compartments $\mathrm{C} 17$ and $\mathrm{C} 19$, and $60^{\circ}$ phase-advanced sinusoidal excitatory currents drive the distal dendrites $\mathrm{C} 35$ and $\mathrm{C} 36$. An asymmetric depolarizing ramp (duration 0.512 to $2.048 \mathrm{~s}$, peaking at $75 \%$ of the duration) is applied either at the soma (as an injected current), midapical dendrites (C22-23), or distal dendrites (C35-36) as an excit-

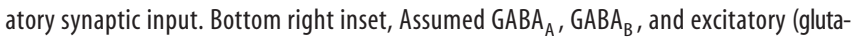
matergic) synaptic conductances at different compartments; small symbol, standard strength; large symbol, double strength (for details, see Materials and Methods and Table 1).

\section{Materials and Methods}

Compartment neuron model. Electrophysiological responses of a CA1 pyramidal cell were simulated using a compartment model represented by first-order differential equations. The main model consists of 38 compartments (Fig. 1). Each compartment is assumed to be a cylindrical cable, and the ith compartment is described by the following:

$$
\begin{gathered}
\frac{G \mathrm{l}_{i, i+1}}{C_{i}}\left(V_{i+1}-V_{i}\right)+\frac{G \mathrm{l}_{\mathrm{i}, \mathrm{i}+1}}{C_{\mathrm{i}}}\left(V_{i-1}-V_{i}\right)=\frac{d V_{i}}{d t}+\frac{G \mathrm{~m}_{i}}{C_{i}}\left(V_{i}-E_{l}\right) \\
+\left(I_{\mathrm{Na}}+I_{\mathrm{A}}+I_{\mathrm{DR}}+I_{\mathrm{h}}+I_{\mathrm{NaP}}+I_{\mathrm{KS}}+I_{\mathrm{inh}}+I_{\mathrm{exc}} / C_{i},\right.
\end{gathered}
$$

where $V_{i-1}, V_{i}$, and $V_{i+1}$ are membrane potential of the $(i-1)$ th, $i$ th, and $(i+1)$ th compartments, respectively; $G_{i}$ and $C_{i}$ are membrane conductance and capacitance of the $i$ th compartments, respectively; $G l_{i, i+1}$ is longitudinal conductance between the $i$ th and the $(i+1)$ th compartments; and $E_{1}$ is leak current reversal potential, normally -70 $\mathrm{mV}$ but adjusted to keep resting membrane potential near $-66 \mathrm{mV}$.
Specific membrane capacitance $\left(C_{\mathrm{m}}\right)$ of $1 \mu \mathrm{F} / \mathrm{cm}^{2}$, specific membrane resistance $\left(R_{\mathrm{m}}\right)$ of $30,000 \Omega \mathrm{cm}^{2}\left(G_{\mathrm{m}}=0.033 \mathrm{mS} / \mathrm{cm}^{2}\right)$, and longitudinal resistivity $R_{i}$ of $200 \Omega \mathrm{cm}$ are assumed. All compartments are assumed to have the same electronic length of $0.03 \lambda$, and $G_{1}=G_{\mathrm{m}} /(0.03)^{2}=$ $1111^{\star} G_{\mathrm{m}} . G \mathrm{~m}_{i} / C_{i}=0.033 \mathrm{~ms}^{-1}$ is the same for all compartments, but coupling strengths between compartments, or $G_{1} / C_{i}$ (Eq. 1) may differ because of different $C_{i}$ (Table 1). Division by $C_{i}$ in Equation 1 converts all currents and conductances as per area since $C_{i}=C_{\mathrm{m}}{ }^{*}$ area of the compartment, where $C_{\mathrm{m}}$ is specific membrane conductance. Units used are $C_{\mathrm{m}}$ (microfarads), voltage (millivolts), time (milliseconds), conductance (millisiemens per square centimeter), and current density (microamperes per square centimeter).

The intrinsic currents $I_{\mathrm{Na}}$ (fast $\mathrm{Na}^{+}$transient current) and $I_{\mathrm{DR}}$ (delayed rectifier current), assumed for thick-circle compartments $(14-23,37,38)$ in Figure 1, follow the description of Hoffman et al. (1997) as follows. $I_{\mathrm{Na}}=G_{\mathrm{Na}}{ }^{*} m^{3} h^{*}\left(V-E_{\mathrm{Na}}\right)$, where $G_{\mathrm{Na}}$ is maximal $\mathrm{Na}^{+}$conductance, and $E_{\mathrm{Na}}$ is $58 \mathrm{mV}$. Parameters $m$ and $h$ are originally defined by Hodgkin and Huxley, and referred to specifically as $I_{\mathrm{Na}} m$ and $I_{\mathrm{Na}} h$, respectively. Each parameter $(m$ or $h)$ is defined by voltage-dependent rate constants $\alpha$ and $\beta$ that determine the time constant $\tau$ and steady-state (subscript ss) value.

$d m / d t=\left(-m+m_{\mathrm{ss}}\right) / \tau_{m}$,

and similar equations for other parameters,

$$
\begin{gathered}
m_{\mathrm{ss}}(V)=\alpha_{m}(V) /\left(\alpha_{m}(V)+\beta_{m}(V)\right) \\
\alpha_{m}(V)=0.364^{*}(V-V \mathrm{NaD}) /(1-(\exp (-V+V \mathrm{NaD}) / 4.5)) \\
\beta_{m}(V)=-0.248^{*}(V-V \mathrm{NaD}) /(1-(\exp (V-V \mathrm{NaD}) / 4.5)) \\
\tau_{m}=0.8 /\left(\alpha_{m}(V)+\beta_{m}(V)\right) \\
\alpha_{h}(V)=0.08^{*}(V+40) /(1-\exp ((-V-40) / 3)) \\
\beta_{h}(V)=-0.005^{*}(V+10) /(1-\exp ((V+10) / 5)) \\
\tau_{h}=1 /\left(\alpha_{h}(V)+\beta_{h}(V)\right) \\
h_{\mathrm{ss}}(V)=1 /(1+\exp ((V+58) / 5)) \\
I_{\mathrm{DR}}=\text { delayed rectifier } \mathrm{K}+\operatorname{current}=G_{\mathrm{K}}{ }^{4}\left(V-E_{\mathrm{K}}\right), \\
n_{\mathrm{ss}}(V)=\alpha_{n}(V) /\left(\alpha_{n}(V)+\beta_{n}(V)\right) \\
\alpha_{n}(V)=0.035^{*}(V+30) /(1-(\exp ((V+30) /-13))) \\
\beta_{n}(V)=0.035^{*}(V+30) /(\exp ((V+30) / 13)-1) \\
\tau_{n}=1 /\left(\alpha_{n}(V)+\beta_{n}(V)\right) .
\end{gathered}
$$

For axonal compartments 18,37 , and $38, V \mathrm{NaD}$ is replaced by $V \mathrm{NaA}$ (Table 1 ) and no $I_{\mathrm{A}}$ is assumed, but $G_{\mathrm{K}}$ is eightfold that of the other compartments. The voltage for half-maximal activation of $I_{\mathrm{Na}}$ at the axon and dendrites are named $V \mathrm{NaA}$ and $V \mathrm{NaD}$, respectively, and will be referred to as the axonal $(V \mathrm{NaA})$ and dendritic $(\mathrm{VNaD})$ spike threshold.

$I_{\mathrm{A}}$ (A current) and $I_{\mathrm{h}}$ (H current) follow the properties described by Leung and Peloquin (2006) as follows:

$$
\begin{gathered}
I_{\mathrm{A}}=\mathrm{K}^{+} \text {A-channel current }=G_{\mathrm{A}} * f_{\mathrm{KA}} * m_{\mathrm{A}}^{4} h_{\mathrm{A}} *\left(V-E_{\mathrm{K}}\right), \\
G_{\mathrm{A}}=I_{\mathrm{A}} \text { maximal conductance, } E_{\mathrm{K}}=-85 \mathrm{mV},
\end{gathered}
$$

where $f_{\mathrm{KA}}$ is a gain factor (channel density) that increases 1.57 -fold for every $100 \mu \mathrm{m}$ increase in depth from the soma toward the apical dendrites, as used by Hoffman et al. (1997), and 2.57-fold for every $100 \mu \mathrm{m}$ increase from the soma toward the basal dendrite. Depths of the dendritic compartments and $f_{\mathrm{KA}}$ are listed in Table 1. $I_{\mathrm{A}}$ parameters are defined as follows:

$$
\begin{gathered}
m_{\mathrm{Ass}}(V)=\alpha_{\mathrm{mA}}(V) /\left(\alpha_{\mathrm{mA}}(V)+\beta_{\mathrm{mA}}(V)\right) \\
\left.\alpha_{\mathrm{mA}}(V)=-0.01 *(V)+34.4\right) /(\exp ((V+34.4) /-21)-1)
\end{gathered}
$$


Table 1. Compartment parameters

\begin{tabular}{|c|c|c|c|c|c|c|c|c|c|c|c|c|}
\hline \multirow[b]{2}{*}{ No. } & \multirow[b]{2}{*}{ Depth $(\mu \mathrm{m})$} & \multirow[b]{2}{*}{$\operatorname{Diam}(\mu \mathrm{m})$} & \multirow[b]{2}{*}{ Angle $\left({ }^{\circ}\right)$} & \multicolumn{2}{|c|}{ Coupling strengths } & \multicolumn{2}{|c|}{ Current } & \multicolumn{2}{|l|}{ Gain } & \multicolumn{3}{|c|}{ Synaptic strengths } \\
\hline & & & & $G l_{i-1, i} / C_{i}$ & $G l_{i+1, i} / C_{i}$ & $I_{\mathrm{Na}}$ & $I_{\mathrm{A}}$ & $f_{\mathrm{h}}$ & $f_{\mathrm{KA}}$ & $\operatorname{lnh}_{\mathrm{A}}$ & $\operatorname{lnh}_{B}$ & Exc \\
\hline 1 & 28.8 & 1.26 & 30 & & $1(2)$ & & & & & & & \\
\hline 2 & 46.7 & 1.26 & 30 & $1(1)$ & $1(3)$ & & & & & & & \\
\hline 3 & 66.9 & 2.00 & 30 & $1(2)$ & $1(4)$ & & & & & & & \\
\hline 4 & 89.4 & 2.00 & 30 & $1(3)$ & $1(5)$ & & & & & & & \\
\hline 5 & 114.8 & 3.18 & 30 & $1(4)$ & $1(6)$ & & & & & & 1 & \\
\hline 6 & 143.1 & 3.18 & 30 & $1(5)$ & $1(7)$ & & & & & & 1 & \\
\hline 7 & 171.5 & 3.18 & 30 & $1(6)$ & $1(8)$ & & & & & 1 & 1 & \\
\hline 8 & 199.8 & 3.18 & 30 & $1(7)$ & $4 / 3(17)$ & & & & & 1 & 1 & \\
\hline 9 & 28.8 & 1.26 & 30 & & $1(10)$ & & & & & & & \\
\hline 10 & 46.7 & 1.26 & 30 & $1(9)$ & $1(11)$ & & & & & & & \\
\hline 11 & 66.9 & 2.00 & 30 & $1(10)$ & $1(12)$ & & & & & & & \\
\hline 12 & 89.4 & 2.00 & 30 & $1(11)$ & $1(13)$ & & & & & & & \\
\hline 13 & 114.8 & 3.18 & 30 & $1(12)$ & $1(14)$ & & & & & & 1 & \\
\hline 14 & 143.1 & 3.18 & 30 & $1(13)$ & $1(15)$ & VNaD & $D$ & 0.39 & 3.5 & & 1 & \\
\hline 15 & 171.5 & 3.18 & 30 & $1(14)$ & $1(16)$ & VNaD & D & 0.34 & 2.8 & 1 & 1 & \\
\hline 16 & 199.8 & 3.18 & 30 & $1(15)$ & $4 / 3(17)$ & VNaD & D & 0.28 & 2 & 1 & 1 & \\
\hline 17 & 240 & 8.00 & 0 & $1 / 3(8,16,18)$ & 2/3 (19) & VNaD & $P$ & 0.2 & 1 & 1 & & \\
\hline 18 & & 3.18 & & $2 / 3(17)$ & $1 / 3(37)$ & VNaA & & & & & & \\
\hline 19 & 286.6 & 5.04 & 0 & $8 / 3(17)$ & $2(20)$ & VNaD & $P$ & 0.29 & 1.7 & 1 & & \\
\hline 20 & 327.8 & 5.04 & 0 & $2(19)$ & $2(21)$ & VNaD & $P$ & 3.8 & 2.4 & 1 & & \\
\hline 21 & 364.3 & 3.18 & 15 & $2(20)$ & $2(22)$ & VNaD & $D$ & 4.5 & 2.9 & 1 & 2 & 1 \\
\hline 22 & 395.9 & 3.18 & 15 & $2(21)$ & $2(23)$ & VNaD & $D$ & 5.1 & 3.5 & 1 & 2 & 1 \\
\hline 23 & 427.5 & 3.18 & 15 & $2(22)$ & $2(24)$ & VNaD & $D$ & 5.8 & 4 & 1 & 2 & 2 \\
\hline 24 & 459.1 & 3.18 & 15 & $2(23)$ & $2(25)$ & & & & & 1 & 2 & 2 \\
\hline 25 & 487.5 & 2.00 & 15 & $2(24)$ & $2(26)$ & & & & & & 2 & 2 \\
\hline 26 & 512.6 & 2.00 & 15 & $2(25)$ & $2(27)$ & & & & & & 1 & 1 \\
\hline 27 & 537.7 & 2.00 & 15 & $2(26)$ & $2(28)$ & & & & & & 1 & \\
\hline 28 & 562.8 & 2.00 & 15 & $2(27)$ & $2(29)$ & & & & & & & \\
\hline 29 & 585.3 & 1.26 & 15 & $2(28)$ & $2(30)$ & & & & & & & \\
\hline 30 & 605.2 & 1.26 & 15 & $2(29)$ & $2(31)$ & & & & & & & \\
\hline 31 & 625.1 & 1.26 & 15 & $2(30)$ & $2(32)$ & & & & & & & \\
\hline 32 & 645.0 & 1.26 & 15 & $2(31)$ & $2(33)$ & & & & & & & \\
\hline 33 & 662.9 & 0.79 & 15 & $2(32)$ & $2(34)$ & & & & & & & \\
\hline 34 & 678.7 & 0.79 & 15 & $2(33)$ & $2(35)$ & & & & & & & \\
\hline 35 & 694.5 & 0.79 & 15 & $2(34)$ & $2(36)$ & & & & & & & \\
\hline 36 & 710.3 & 0.79 & 15 & $2(35)$ & & & & & & & & \\
\hline 37 & & 2.00 & & 2/3 (18) & $1 / 2(38)$ & VNaA & & & & & & \\
\hline 38 & & 2.00 & & $1 / 2(37)$ & & VNaA & & & & & & \\
\hline
\end{tabular}

From left: Compartment number, depth from alvear surface, diameter (Diam) of compartment, angle $\left(^{\circ}\right)$ of long axis of soma-dendritic compartment with the vertical, coupling strength of ith compartment $\left(G_{1} / C_{i}\right.$ in units of $18.33 \mathrm{~ms}{ }^{-1}$ with

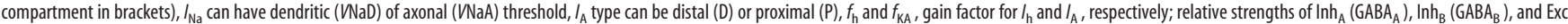
(excitation) during afferent stimulation.

$$
\begin{gathered}
\beta_{\mathrm{mA}}(V)=0.01 *(V+34.4) /(\exp ((V+34.4) / 21)-1) \\
\tau_{\mathrm{mA}}=0.2 \mathrm{~ms} \\
\alpha_{\mathrm{hA}}(V)=-0.01 *(V+58) /(\exp ((V+58) / 8.2)-1) \\
\beta_{\mathrm{hA}}(V)=0.01 *(V+58) /(\exp ((V+58) /-8.2)-1) \\
h_{\mathrm{Ass}}(V)=\alpha_{h}(V) /\left(\alpha_{h}(V)+\beta_{h}(V)\right) \\
\tau_{h}=5 \mathrm{~ms} \text { for } V<-20 \mathrm{mV}, \text { and }\left(5+0.26^{\star}(V+20)\right)
\end{gathered}
$$

for $V>-20$.

The proximal compartments (Table 1) have higher voltage threshold for $I_{\mathrm{A}}$ activation, as defined by the $\alpha_{\mathrm{mA}}(V)$ and $\beta_{\mathrm{mA}}(V)$ parameters below (Hoffman et al., 1997):

$$
\begin{gathered}
\alpha_{\mathrm{mA}}(V)=-0.01 *(V+21.3) /(\exp ((V+21.3) /-35)-1) \\
\beta_{\mathrm{mA}}(V)=0.01 *(V+21.3) /(\exp ((V+21.3) / 35)-1)
\end{gathered}
$$

The hyperpolarization-induced cation current $I_{\mathrm{h}}$ is described by a single parameter $\kappa$ (Gasparini et al., 2004) such that

$I_{\mathrm{h}}=G_{\mathrm{ho}} f_{\mathrm{h}}{ }^{\star} \kappa^{\star}(V+30)$,

$$
\begin{gathered}
\alpha_{\kappa}(V)=\exp \left(0.08316^{*}(V+75)\right) \\
\beta_{\kappa}(V)=\exp \left(0.03326^{*}(V+75)\right) \\
\tau_{\kappa}=49.8^{*} \beta_{\kappa}(V) /\left(1+\alpha_{\kappa}(V)\right) \\
\kappa_{\text {ss }}(V)=1 /(1+\exp ((V+81) / 8)) .
\end{gathered}
$$$$
\text { with reversal potential of }-30 \mathrm{mV} \text { and } G_{\mathrm{h} 0}=0.2 \mathrm{mS} / \mathrm{cm}^{2}
$$

$f_{\mathrm{h}}$ is a gain factor (channel density) that is 1 at the soma, increases twofold from 0 to $100 \mu \mathrm{m}$, and another twofold from 100 to $200 \mu \mathrm{m}$ (Magee, 1998), as listed for the compartments in Table 1.

With an electrotonic length constant $\lambda=1375 \mu \mathrm{m}$, the soma compartment 17 is assumed to be a cylinder of $8 \mu \mathrm{m}$ diameter and $51 \mu \mathrm{m}$ length $(0.03 \lambda)$, and the unbranched apical dendritic shaft (compartments 19 and 20) of $5 \mu \mathrm{m}$ diameter and $82 \mu \mathrm{m}$ length is equivalent to $0.06 \lambda$. Two primary basal dendritic branches are assumed to be $3.2 \mu \mathrm{m}$ diameter. The actual depths of the dendritic compartments with respect to the alvear surface (Table 1) are relevant for field potential generation and not for intracellular voltage simulations. These compartment depths assume that (1) bifurcation of the primary and secondary dendrites occurs every $80-100 \mu \mathrm{m}$ and satisfies the $\Sigma d^{3 / 2}$ rule of Rall (1964), and (2) the two basal dendritic branches are angled at $30^{\circ}$ from the vertical, while 

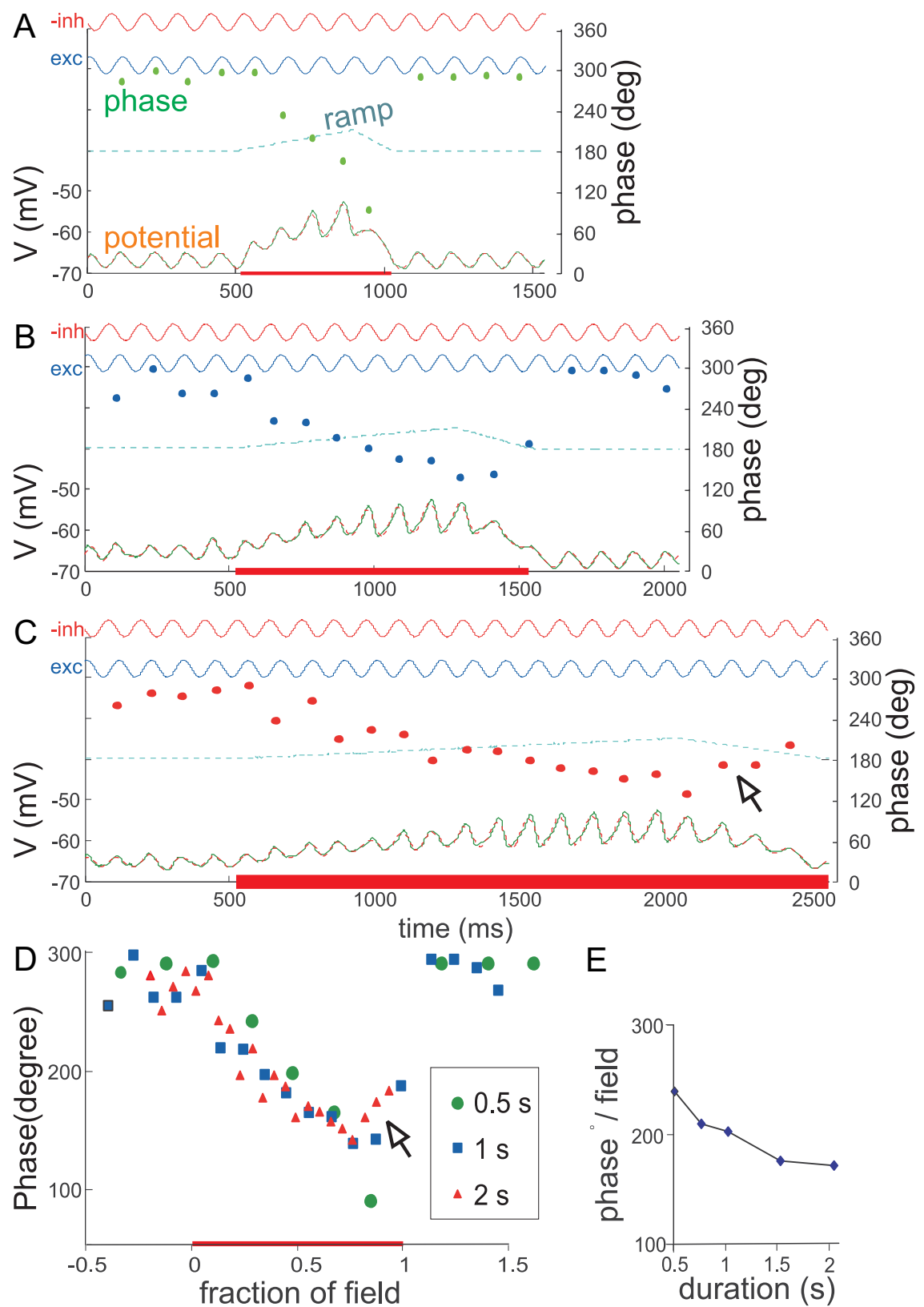

Figure 2. Subthreshold model of place cell show phase precession that depends on animal's position in the place field. An animal is assumed to run through a fixed one-dimensional place field at three different velocities, traversing the field in $0.512 \mathrm{~s}(\boldsymbol{A})$, $1.024 \mathrm{~s}(\boldsymbol{B})$, and $2.048 \mathrm{~s}(\boldsymbol{C})$, respectively. The depolarizing ramp conductance ( $\mathrm{RpG}=1.5$ ) is assumed to be the same function except for time expansion, excitatory synaptic noise (Poisson's distributed with 5 ms mean) is added to the distal dendrites, and rhythmic $(9 \mathrm{~Hz})$ distal-dendritic excitatory $(\mathrm{Se}=0.1)$ and proximal inhibitory driving $(\mathrm{Si}=0.2)$ are given. $\boldsymbol{A}$, In each panel, reversed inhibitory ( $-\mathrm{inh}$ ) and excitatory (exc) conductance drive function, phase (filled circles, axis on right), depolarizing ramp in the place field (thick red line on the time axis), and the somatic membrane potential (unfiltered green trace, and low-pass filtered, red dashed trace) are plotted. The peaks of the " $-\mathrm{inh}^{\prime \prime}$ function are $\pm 180^{\circ}$, and the phase of each peak of the MPOs is measured with reference to this function. $\boldsymbol{B}, \boldsymbol{C}$, Phase decrease within the place field is smaller for slower runs, and with a slight reversal of phase decline (arrow). D, Phase plotted with the place field normalized to unity shows similar phase precession across all speeds during the initial $85 \%$ of the place field and a small, reverse precession (arrow) during the rest of the place field. $\boldsymbol{E}$, Magnitude of linear regression slope of phase in the initial $85 \%$ of place field (units of degrees/field) plotted with the duration of run through the place field.

two apical dendritic branches angled at $15^{\circ}$ come from the apical dendritic shaft represented by compartment 20 . The two daughter apical branches are not shown in Figure 1 but are lumped into a single compartment 21, since the two compartments together behave electrotonically as a cable of uniform diameter with the mother branch (compartment 20). Similar assumptions are made for further bifurcations along the apical and basal dendritic branches.
$I_{\mathrm{NaP}}=G_{\mathrm{NaP}}{ }^{*} m^{*}\left(V-E_{\mathrm{Na}}\right)=$ persistent (non-inactivating) $\mathrm{Na}^{+}$current, where $G_{\mathrm{NaP}}=$ maximal persistent $\mathrm{Na}^{+}$conductance (French et al., 1990, Magistretti and Alonso, 1999; Vervaeke et al., 2006).

$$
\begin{gathered}
d m^{\prime} / d t=\left(m_{\mathrm{ss}}^{\prime}-m^{\prime}\right) / \tau_{m^{\prime}}, \text { with } \\
\tau_{m^{\prime}}=1 \mathrm{~ms} \text {, and } \\
m_{\mathrm{ss}}^{\prime}(V)=1 /(1+\exp ((-V-50) / 5)) .
\end{gathered}
$$

An $I_{\mathrm{NaP}}$ slow inactivation (time constant, $\sim 6$ s), as described by Magistretti and Alonso (1999), is not used since its inclusion does not affect the main results.

$I_{\mathrm{KS}}=G_{\mathrm{KS}}{ }^{\star} n^{\prime}\left(V-E_{\mathrm{K}}\right)=$ M-type $\mathrm{K}^{+}$current is described according to Yamada et al. (1989), with $d n^{\prime} / d t=\left(n_{\mathrm{ss}}^{\prime}-n_{\mathrm{s}}\right) / \tau_{n^{\prime}}$,

$$
\begin{aligned}
1 / \tau_{n^{\prime}}= & (\exp ((V+35) / 40) \\
& +\exp (-(V+35) / 20)) / 81, \text { and } \\
n_{\mathrm{ss}}^{\prime}(V)= & 1 /(1+\exp ((-V-35) / 10)) .
\end{aligned}
$$

The time constants for $I_{\mathrm{KS}}$ are calculated as 33 and $24 \mathrm{~ms}$ at holding voltages of -45 and -55 $\mathrm{mV}$, respectively, assumed for $37^{\circ} \mathrm{C}$. If a temperature factor Q10 of 5 is assumed, time constants in the present model are of similar magnitudes as those experimentally measured by Halliwell and Adams (1982) in CA1 pyramidal cells (92 and 47 $\mathrm{ms}$ at $30^{\circ} \mathrm{C}$ ) and by Wang et al. (1998) in dissociated rat sympathetic ganglion (132 and $115 \mathrm{~ms}$ at room temperature).

Simulation of spiking. Subthreshold MPOs without spikes are simulated by using axonal $(V \mathrm{NaA})$ and dendritic spike threshold $(V \mathrm{NaD})$ of greater than $-32 \mathrm{mV}$, unless otherwise indicated. This is necessary for showing the properties of MPOs below the spike threshold. $\left(G_{\mathrm{Na}} / C_{i}\right),\left(G_{\mathrm{KA}} / C_{i}\right)$, and $\left(G_{\mathrm{DR}} / C_{i}\right)$ are 60,24 , and $15 \mathrm{~ms}^{-1}$, respectively. For the normal spiking condition, which simulates both MPOs and spike precession, the spike thresholds are set at $V \mathrm{NaD}=-34$ and $V \mathrm{NaA}=-39$, and $V_{\text {noise }}$ is added to $V \mathrm{NaA}$, with $V_{\text {noise }}$ assumed to be Poisson-distributed with a mean of $4 \mathrm{mV}$ and to change every millisecond. The Poissondistributed $V_{\text {noise }}$ adds variability to spiking, giving it a low rate at rest $(0.05$ to $0.1 \mathrm{~Hz}$ at approximately $-65 \mathrm{mV}$ somatic membrane potential), and not necessarily firing at consecutive MPO peaks; $\left(G_{\mathrm{DR}} / C_{i}\right)$ is increased to 30 $\mathrm{ms}^{-1}$ when $V_{\text {noise }}$ is added, to limit burst activity, but all other parameters remain the same.

Excitatory and inhibitory driving and current injection. Step currents of amplitude SA and $>2$ s duration are injected into the soma. Injected somatic currents also include a ZAP function (Hutcheon and Yarom, 2000) with time $t$, of the form $\mathrm{SA}^{*} \sin \left(2 \pi f(t)^{\star} t\right)$ over a time period $T$, where $S A=$ amplitude, and the swept frequency increases from zero to a maximum of $f_{\mathrm{m}}, f(t)=f_{\mathrm{m}}{ }^{*} t / T$, for $0<=t<=T$; with $f_{\mathrm{m}}=20$ or $40 \mathrm{~Hz}$. The input current and soma voltage output are resampled every millisecond (for at least 4096 points), and the amplitude and phase of the complex impedance (voltage/current) are estimated from Fourier transform.

An asymmetric ramp-like excitation (Mehta et al., 2002; Harvey et al., 2009), of duration $T$ and peaking at $0.75 T$ from onset is assumed. This 
ramp is applied with peak conductance RpG at the distal dendrites (compartments 35 and 36), or at the middle dendrites (compartments 22 and 23 ), or as an injected current (peak RpI at the soma); the ramp amplitude is adjusted to yield $<15 \mathrm{mV}$ depolarization at the soma. Noise inputs are added to most simulations. For a distal ramp, Poisson-distributed impulses (mean interval, $5 \mathrm{~ms}$ ) are applied to excite the distal dendrites with a peak conductance of ExG and single decay rate constant of $0.35 \mathrm{~ms}^{-1}$. For a proximal current ramp, current noise is added with Poisson distribution (with a mean interval of $5 \mathrm{~ms}$ ), amplitude ExI and decay rate constant $0.35 \mathrm{~ms}^{-1}$. Typical noise magnitudes are $\mathrm{ExG}=0.05$ to 0.4 , and $\mathrm{ExI}=5$ (for somatic ramp), or ExI $=0.2^{\star} \mathrm{SA}$ (for ZAP function input).

A rhythmic inhibitory conductance $\mathrm{Si}^{\star} \sin \left(2 \pi f^{\star} t\right)$ is applied to the proximal compartments, and an excitatory conductance driving function $\mathrm{Se}^{*} \sin \left(2 \pi f^{*} t+\phi\right)$ is applied to the dendrites (Fig. 1), where $f=$ $5-12 \mathrm{~Hz}, \mathrm{Si}$ is peak inhibitory conductance, and Se is peak excitatory conductance. The driving functions are sinusoidal, assuming increase and decrease from a tonic level. Proximal-inhibitory and distalexcitatory driving functions are consistent with models of generation of extracellular theta rhythm (Leung, 1984; Kamondi et al., 1998). The excitatory drive is assumed to be $60^{\circ}(=\phi)$ advanced of the inhibitory drive (Leung, 1984). This results in firing of pyramidal cells at $\sim 250^{\circ}$ phase during baseline (see Fig. 5B), while maximal inhibition occurs at 0 or $360^{\circ}$. For display in the figures below, the rhythmic inhibitory driving is reversed in polarity [i.e., shown as $-\mathrm{Si}^{\star} \sin \left(2 \pi f^{\star} t\right)$ ] to facilitate a direct comparison with the membrane potential response (since positive or high inhibition results in negative membrane potential response).

The MATLAB differential equation solver [ODE23 using Runge-Kutta $(2,3)$ formula] uses variable time steps $(<0.09 \mathrm{~ms})$, and the resulting membrane voltages are linearly extrapolated and sampled at $1 \mathrm{~ms}$ interval. If spikes are not present, the MPO signal is the soma voltage after low-pass $(<16 \mathrm{~Hz})$ digital filtering that does not shift the phase. In the presence of spikes, defined as sharp transients above $-30 \mathrm{mV}$ in the wide band simulated soma voltage, the spike peaks are first identified. A MPO signal without spikes is derived from the $1 \mathrm{~ms}$ resampled voltage data, after each spike peak and two adjacent points (total of $3 \mathrm{~ms}$ duration) are removed and replaced by the average voltage before and after the removed points. The latter procedure removes the spike peaks but spike afterpotentials may remain. The peaks of the inhibitory driving function are used as the reference (zero phase) for measuring phase shift of the MPO or spike peaks. Power of the MPOs at the soma is estimated by Fourier transform during baseline (called base power) and for the whole duration of the depolarizing ramp (called place power); the same duration (typically $1024 \mathrm{~ms}$ ) is used to construct the power spectra for baseline and place.

To study whether phase precession is disrupted by evoked inhibition and excitation of CA3 afferents, singlepulse stimulation (impulse function) of the associational and commissural afferents is assumed to activate excitatory conductance in the midapical dendrites (Fig. 1, inset; Table 1) with maximal conductance of $1.13 \mathrm{mS} / \mathrm{cm}^{2}$ at compartments $21,22,25$, and 26, and $2.27 \mathrm{mS} /$ $\mathrm{cm}^{2}$ at compartments 23 and 24. Single-pulse evoked $\mathrm{GABA}_{\mathrm{A}}$ and $\mathrm{GABA}_{\mathrm{B}}$ inhibitory conductances are described by the function $\left(t-t_{\mathrm{d}}\right) * \exp (-t-$ $\left.t_{\mathrm{d}} / \tau\right) ; t_{\mathrm{d}}=2, \tau=33.3 \mathrm{~ms}$ for $\mathrm{GABA}_{\mathrm{A}}$ conductance function acting on proximal compartments (Fig. 1, inset) that peaks at $2.11 \mathrm{mS} / \mathrm{cm}^{2}$. For $\mathrm{GABA}_{\mathrm{B}}$ conductance, $t_{\mathrm{d}}=20$ and $\tau=192 \mathrm{~ms}$, and it peaks at $0.18 \mathrm{mS} / \mathrm{cm}^{2}$ in

B
Table 2. Phase precession of subthreshold MPOs in preferred model $\left(G_{\mathrm{NaP}}=\mathbf{0 . 8}\right.$; $G_{\mathrm{KS}}=8$ ) with different input parameters, and depolarization ramp induced by distal dendritic excitation

\begin{tabular}{rlllllllc}
\hline $\begin{array}{l}\text { Duration } \\
\text { (ms) }\end{array}$ & Si & Se & $\begin{array}{l}\text { Regline } \\
\text { slope }(\% / s)\end{array}$ & $\begin{array}{l}\text { Degrees } \\
\text { per field }\end{array}$ & $R^{2}$ & $\begin{array}{l}\text { Base } \\
\text { power }\end{array}$ & $\begin{array}{l}\text { Place } \\
\text { power }\end{array}$ & $\begin{array}{c}\text { Power } \\
\text { ratio }\end{array}$ \\
\hline 512 & 0.2 & 0.1 & -465 & 238 & 0.99 & 912 & 1996 & 2.2 \\
2048 & 0.2 & 0.1 & -85 & 174 & 0.93 & 855 & 1340 & 1.6 \\
1024 & 0.2 & 0.1 & -198 & 203 & 0.97 & 955 & 1521 & 1.6 \\
1024 & 0.2 & 0 & -110 & 110 & 0.85 & 112 & 1930 & 17.2 \\
1024 & 0 & 0.1 & -67 & 68 & 0.53 & 1287 & 525 & 0.41 \\
1024 & 0.4 & 0.2 & -172 & 180 & 0.95 & 4114 & 6260 & 1.5 \\
1024 & 0.4 & 0 & -89 & 91 & 0.84 & 415 & 7642 & 18.4 \\
1024 & 0 & 0.2 & -44 & 45 & 0.40 & 5180 & 1906 & 0.37 \\
\hline
\end{tabular}

Resting membrane potential is $-66 \mathrm{mV}$, and average depolarization during ramp is $-60 \mathrm{mV}$. Rhythmic $(9 \mathrm{~Hz})$ excitatory and/or inhibitory inputs have strengths Se and Si, respectively; excitatory input is $60^{\circ}$ advanced of inhibitory input. Slope of regression (Reg) line $(\%)$ is estimated by linear regression, correlation coefficient $R$, of the initial $85 \%$ of the ramp duration, or expressed in degrees $\left({ }^{\circ}\right.$ ) divided by the place field (complete place field $=1$ ). Power of the theta band $(4-12 \mathrm{~Hz}$ ) is integrated during baseline (base power) and during the ramp (place power), in unit of square millivolts per hertz; power ratio is place power/base power. Values are average of three to eight simulations.
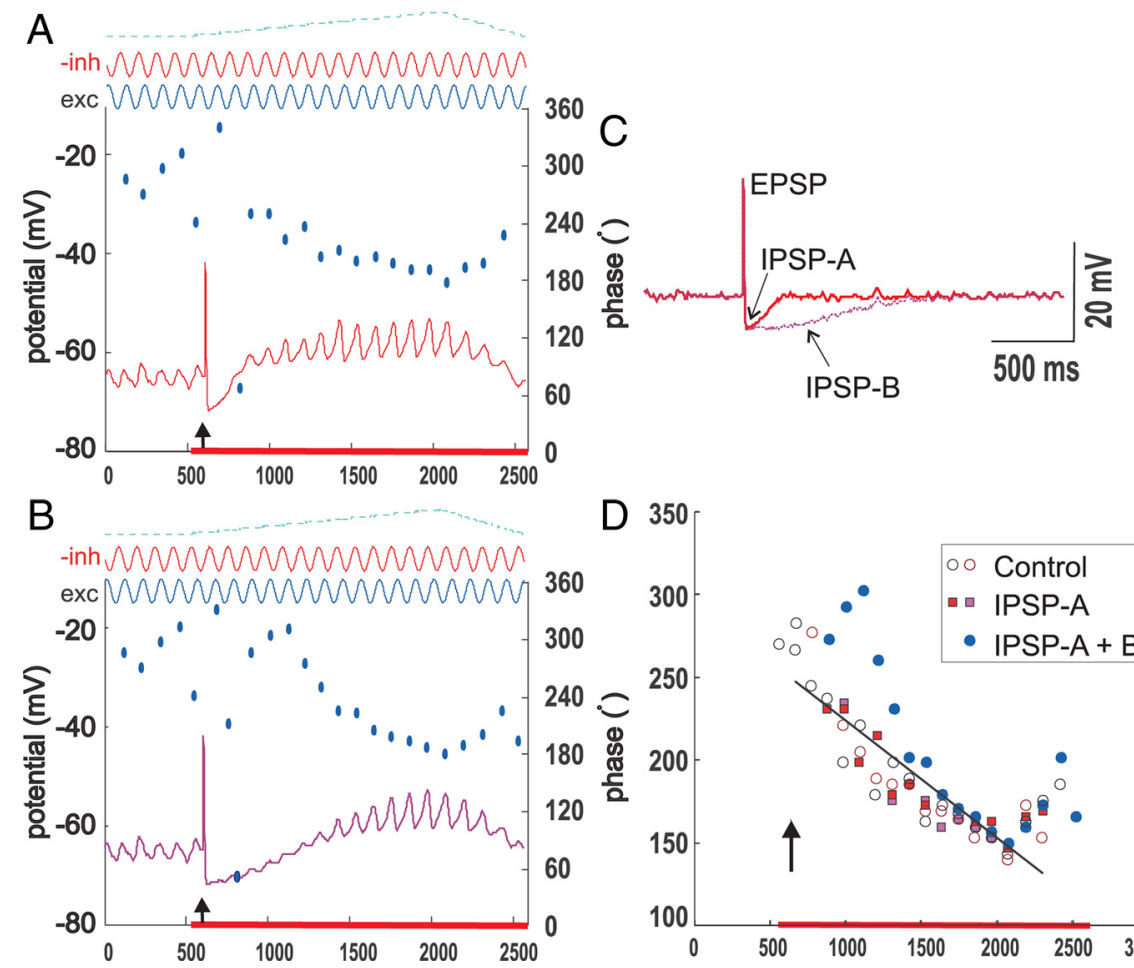

D 350

Figure 3. Perturbation of the subthreshold model with evoked inhibition only transiently disrupts phase precession of the subthreshold membrane potential oscillations. Afferent pulse stimulation given at $600 \mathrm{~ms}$ (up arrow), after onset of the ramp (place field) at $512 \mathrm{~ms}$, disrupts phase for $\sim 200 \mathrm{~ms}$ when $G_{A B A_{A}}$ inhibitory conductance is evoked $(A)$, and for $\sim 800$ ms when both GABA $A_{A}$ and $G A B A_{B}$ inhibitory conductances are evoked (B). C, IPSP with GABA $A_{A}$ conductance alone (IPSP-A; red trace), or with $G_{A B A_{B}}$ conductance (purple dotted trace; IPSP-A+B); $30 \mathrm{mV}$ EPSP precedes the IPSP. D, Phase precession during the place field without afferent stimulation ("control"; two simulations with open circles), with evoked IPSP-A (two simulations with square symbols), or evoked IPSP-A + B (solid circles). Regression line for control data has slope of $-70^{\circ} / \mathrm{s}, R^{2}=0.8 . G A B A_{A}$ conductance is assumed for the soma and proximal dendrites and $G A B A_{B}$ conductance for the middendrites (Fig. 1, inset).

dendritic compartments with standard strength and $0.36 \mathrm{mS} / \mathrm{cm}^{2}$ in compartments with double strength; $\mathrm{GABA}_{\mathrm{B}}$ conductance strengths are listed in Table 1.

\section{Results}

Phase code of place location

To clearly visualize the dynamics of the subthreshold MPOs, simulations using a high spike threshold $(V \mathrm{NaD}=V \mathrm{NaA}=-28)$ are first presented. During baseline, before an animal moves into 

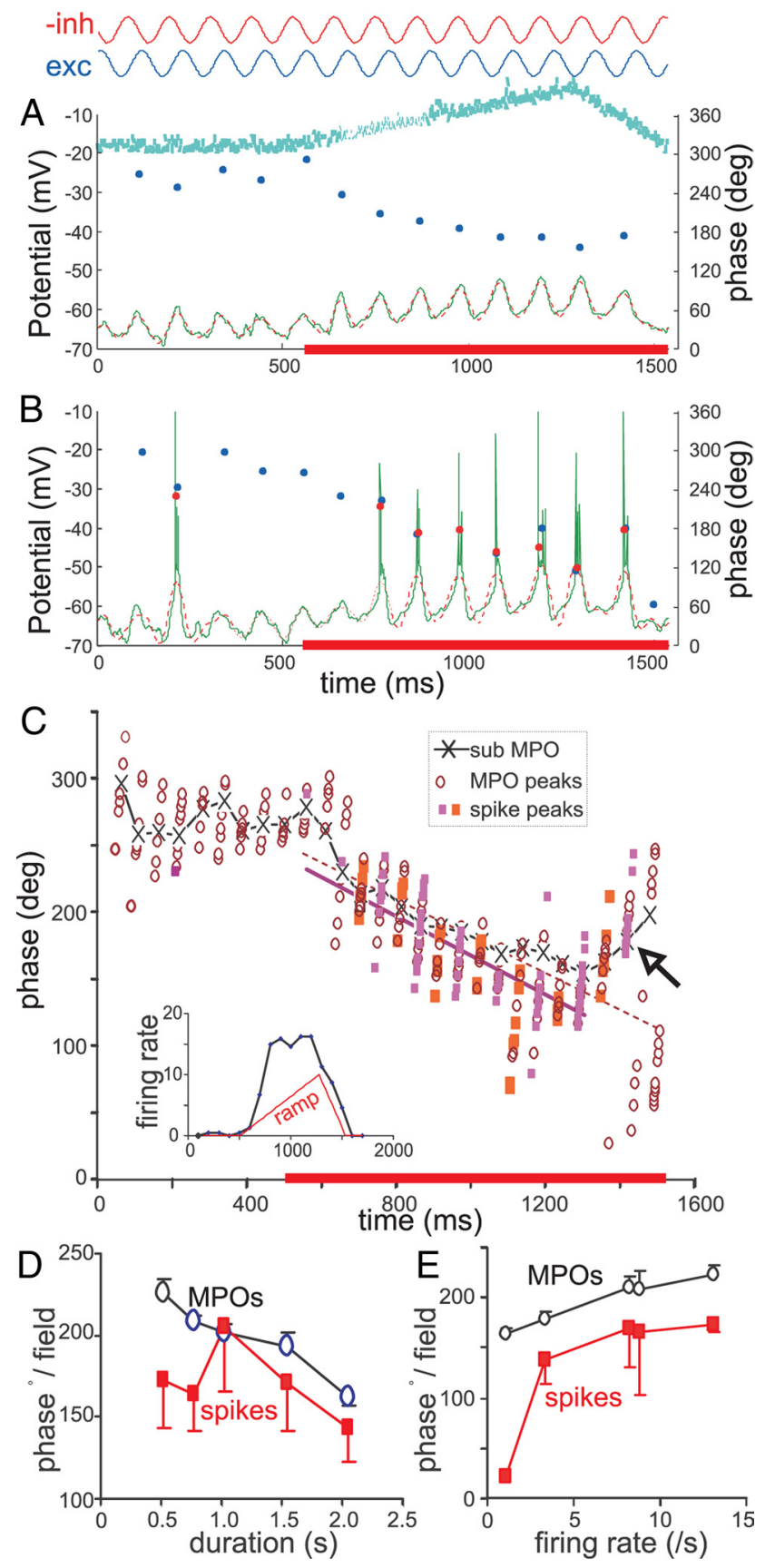

Figure 4. Spike precession resembles MP0 peak precession in spiking model $(\mathrm{Se}=0.2 ; \mathrm{Si}=0.4)$, during $512 \mathrm{~ms}$ baseline and $1024 \mathrm{~ms}$ place field (red line on time axis). $A$, From top to bottom traces, depolarizing ramp with distal apical dendritic noise, excitatory (exc) and reversed inhibitory (-inh) drive, phase at MPO peaks (filled blue circles) or spikes (filled red circles), continuous traces (bottom) of unfiltered (green) and filtered $(0-16 \mathrm{~Hz})$ somatic potentials. Spiking suppressed with high axon spike threshold $(\mathrm{VaA}=\mathrm{VNaD}=-34 \mathrm{mV}) . \mathbf{B}, \mathrm{MPO}$ traces and phase with normal spike thresholds $(V \mathrm{NaA}=-39 \mathrm{mV} ; \mathrm{VNaD}=-34 \mathrm{mV})$, and singleor double spikes fire near the peak of the MPOs.C, Phase plot, showing the average phase of the subthreshold MPO peaks (sub MPO) with high axon spike threshold (12 trials, Xsymbols linked by a dash line), and scatter plot of the phase of MPO (open circles) and spike peaks (solid square symbols) with normal axon spike threshold (12 trials). Note high and low spike threshold simulations yield a similar linear regression slope of the phase precession for MPO peaks (dotted line; $-146^{\circ} / s ; R^{2}=0.55$ ) and spikepeaks (thick line; $-138^{\circ} / \mathrm{s} ; R^{2}=0.51$ ) with the latter line displaced downward from the former. The inset shows the firing rate running average (in spikes/second, integrated every 0.2 s). D, Magnitude of linear regression slope of phase of the MPO peaks or spikes during the initial $75 \%$ of place field (units of degrees/field) for different run duration. $\boldsymbol{E}$, Regression slopes for a fixed (1024 ms) duration run plotted versus different average firing rate within the place field simulated by varying spike thresholds. Thresholds from low to high firing rate are, respectively, $\mathrm{WaA}=-36.5,-37.5,-39$ (above with $\mathrm{VNaD}=-34$ ), then $\mathrm{WNaA}=-39$ and -40 (both with $\mathrm{WaD}=-36$ ); units are in millivolts. the place field of the simulated neuron (Fig. 2A), combined excitatory and inhibitory rhythmic inputs result in MPO peaks of $\sim 290^{\circ}$ phase with respect to the inhibitory conductance driving function. In the place field, a distal-dendritric excitatory ramp is assumed. Phase precession of the MPO peaks starts approximately one theta cycle after ramp onset and continues after the peak of the ramp (Fig. $2 A$ ). In addition, the amplitude of the MPOs gradually increases during the ramp (Fig. $2 A$ ). After the place field is traversed, rapid restoration of the baseline phase occurs. If the duration of running through the field is longer (Fig. $2 B, 1024 \mathrm{~ms} ; C, 2048 \mathrm{~ms}$ ), the decrease of phase with time becomes more gradual (Table 2). When MPO phase is plotted as a fraction of the animal's distance in a one-dimensional place field, assuming constant speed, a similar phase precession function with distance is found for different running speeds (Fig. 2D). The phase decrease with distance is approximately linear with time for the initial $85 \%$ of the place field, and then the phase may increase slightly during the last $15 \%$ of the field (Fig. 2C,D, open arrow). For a 512 ms run duration, no phase increase is found; this relates to the observation that the phase decrease appears to persist for one more theta cycle, regardless of ramp duration, after the peak of the ramp at $75 \%$ of the field. The slope of the linear regression line changes slowly with duration (run speed) - it decreases $27 \%$ from $238^{\circ}$ to $174^{\circ}$ per place field while the duration changes fourfold (Fig. 2E).

Evoked inhibition only transiently disrupts phase precession To test whether phase precession is disrupted by a strong afferent stimulation (Zugaro et al., 2005), the subthreshold model is subjected to an afferent stimulation pulse that generates an EPSP followed by an $\operatorname{IPSP}_{\mathrm{A}}$ mediated by $\mathrm{GABA}_{\mathrm{A}}$ receptors, with or without a $\mathrm{GABA}_{\mathrm{B}}$ receptor-mediated $\mathrm{IPSP}_{\mathrm{B}}$. During the strong $\operatorname{IPSP}_{A}$, all synaptic responses are shunted and phase could not be estimated from the MPO peaks for approximately two theta cycles. In experimental situation, spikes were silent for $200-250 \mathrm{~ms}$ (Zugaro et al., 2005). As the IPSP ${ }_{\mathrm{A}}$ subsides, the simulated MPO amplitudes increase and phase precession continues, as if no IP$\mathrm{SP}_{\mathrm{A}}$ had occurred (Fig. 3A). If a prolonged IPSP $\mathrm{B}_{\mathrm{B}}$ is evoked, the MPO phase is disrupted for approximately seven theta cycles $(\sim 0.8 \mathrm{~s})$ after the stimulus and then the phase and its precession resume at the normal magnitude and rate (Fig. $3 B, D$ ). Disruption of phase coding by an IPSP ${ }_{\mathrm{B}}$ has not been shown experimentally. The effect of the evoked inhibition does not depend on the timing of the inhibition in relation to the ramp. At all onset times, an evoked $\operatorname{IPSP}_{\mathrm{A}}$ disrupted the phase precession for approximately two theta cycles, and an evoked $\mathrm{IPSP}_{\mathrm{B}}$ disrupted the phase for approximately seven theta cycles.

\section{Phase precession of spike follows that of MPOs}

When spiking occurs, they show a gradual phase precession in the place field, with each spike generally firing near an MPO peak (Fig. $4 B$ ), and thus, spikes and the filtered MPO peaks precess at similar rates (Fig. 4B,C; Table 3). When spikes are suppressed by setting a high spike threshold (Fig. 4A), subthreshold MPOs (sub MPO) still precess at a similar rate as the filtered MPOs during normal spiking (Fig. 4, compare $A, B$, and group data plotted in $C)$. Despite the asymmetric depolarization ramp, the average spike rate within the field is symmetric (Fig. $4 C$, inset), as was observed experimentally (O'Keefe and Recce, 1993). As shown for subthreshold MPOs (Fig. 2D), MPOs and spike precession during normal spiking condition show a small dependence on run duration (Fig. 4D). Phase precession of spikes is generally similar to that of MPOs for run duration of $1-2 \mathrm{~s}$, but it is more 
Table 3. Phase precession parameters simulated in model with Poisson distributed axon spike noise, for different rhythmic inputs, excitatory input with strength $\mathrm{Se}$ and inhibitory input with strength $\mathrm{Si}$, and with or without $I_{\mathrm{h}}$ conductance

\begin{tabular}{|c|c|c|c|c|c|}
\hline Condition & RMP & $\begin{array}{l}\text { MP0 reg line } \\
\text { slope }(\% / s)\end{array}$ & $R^{2}$ & $\begin{array}{l}\text { Spike reg line } \\
\text { slope }(\% / s)\end{array}$ & $R^{2}$ \\
\hline \multicolumn{6}{|l|}{ With $/ \mathrm{h}$} \\
\hline $\mathrm{Si}=0.4$ and $\mathrm{Se}=0.2$ & -64.5 & $-210 \pm 9$ & 0.84 & $-185 \pm 24$ & 0.64 \\
\hline $\mathrm{Si}=0.4$ only & -64.5 & $-102 \pm 8$ & 0.73 & $-122 \pm 8$ & 0.72 \\
\hline $\mathrm{Se}=0.2$ only & -64.5 & $-137 \pm 20$ & 0.23 & $-151 \pm 81$ & 0.12 \\
\hline \multicolumn{6}{|l|}{ Without $I_{\mathrm{h}}$} \\
\hline $\mathrm{Si}=0.4$ and $\mathrm{Se}=0.2$ & -65.4 & $-233 \pm 5$ & 0.79 & $-201 \pm 22$ & 0.77 \\
\hline
\end{tabular}

Normal $I_{\mathrm{h}}$ conductance $G_{\mathrm{h} 0}=0.1$; resting membrane potential (RMP) is adjusted by the leak current equilibrium potential to a similar RMP after making $G_{h 0}=0(n o / h)$. Note similar MPO and spike precession slopes (mean \pm SEM) with or without $I_{h}$; precession slope during normal spiking condition is fitted for the initial $75 \%$ of the ramp duration. For each condition, spike precession is typically more variable than MPO precession ( $n=5$ simulations, except the $\mathrm{Se}=0.2$ only condition consists of four groups each of 10 simulations).

variable (Fig. 4D, Table 3 ) as expected from the addition of spike threshold noise (see Materials and Methods).

The relationship between spike rate and phase precession in the place field is investigated by varying spike thresholds at the axon and/or dendrites ( $V \mathrm{NaA}$ and $V \mathrm{NaD}$ do not vary in time in the simulations). Varying spike thresholds changes the mean firing rate, but theta phase precession of the spikes and MPOs in the place field is found with all firing rates, except spike phase precession is minimal at a firing rate of $<2 / \mathrm{s}$ (Fig. $4 E$ ). There is a small increase of precession per field with firing rate change from 3 to $13 \mathrm{~Hz}$, but the simulated data are consistent with the presence of spike phase precession during runs with low and high firing rates (Huxter et al., 2003).

A small phase precession reversal after the peak of the depolarizing ramp is also found for the simulated spikes during long-duration runs (Figs. $4 C, 5 B, D$, open arrow). However, experimentally, spike phase precession within the place field was reported to continue after spike firing decreased (O'Keefe and Recce, 1993; Huxter et al., 2003), and some cells even showed steeper phase precession near the end of the place field [Skaggs et al. (1996), their Fig. 7]. In the present model, continuous spike precession without reversal can be achieved if inhibitory driving is terminated, for example, at a time near the peak of the depolarizing ramp [Fig. $5 C$, asterisk $\left(^{*}\right)$ ]. The latter results in earlier cessation of firing (Fig. 5 , compare $C$ with $B$; $D$, inset), but for the few spikes that fire after the ramp peak (Fig. 5C,D, solid arrow), they fire near the peak of a membrane potential that oscillates at $\sim 12 \mathrm{~Hz}$. These $\sim 12 \mathrm{~Hz}$ oscillations are near the natural frequency of MPOs induced by the depolarization ramp (Fig. $5 A$ ); and the oscillations are there whether excitatory driving is present or not. A fast phase precession at a rate of $0.85^{\circ} / \mathrm{ms}$ (Fig. $5 D$, dashed line at 2000-2200 ms) is caused by the difference between the driving frequency $(9 \mathrm{~Hz})$ and the natural frequency.

\section{Rhythmic inhibition and depolarization result in power increase and precession of MPOs}

As described above, when combined rhythmic excitation and inhibition are given during the depolarizing ramp, there is a gradual phase precession of the MPOs and spikes (Fig. 6A1). The amplitude of the MPOs increases in the place field, as shown by the power spectrum in the place field (place) compared with that during baseline (base) (Fig. 6A2). In the place field compared with baseline, the peak frequency of the MPOs is increased [Fig. $6 A 2$, asterisk $\left.\left({ }^{*}\right)\right]$, together with a clear second harmonic of the theta driving frequency (Fig. 6A2, arrow).

When driven by rhythmic excitation only, phase precession of MPOs during the depolarizing ramp is small (Fig. 6B1), com-
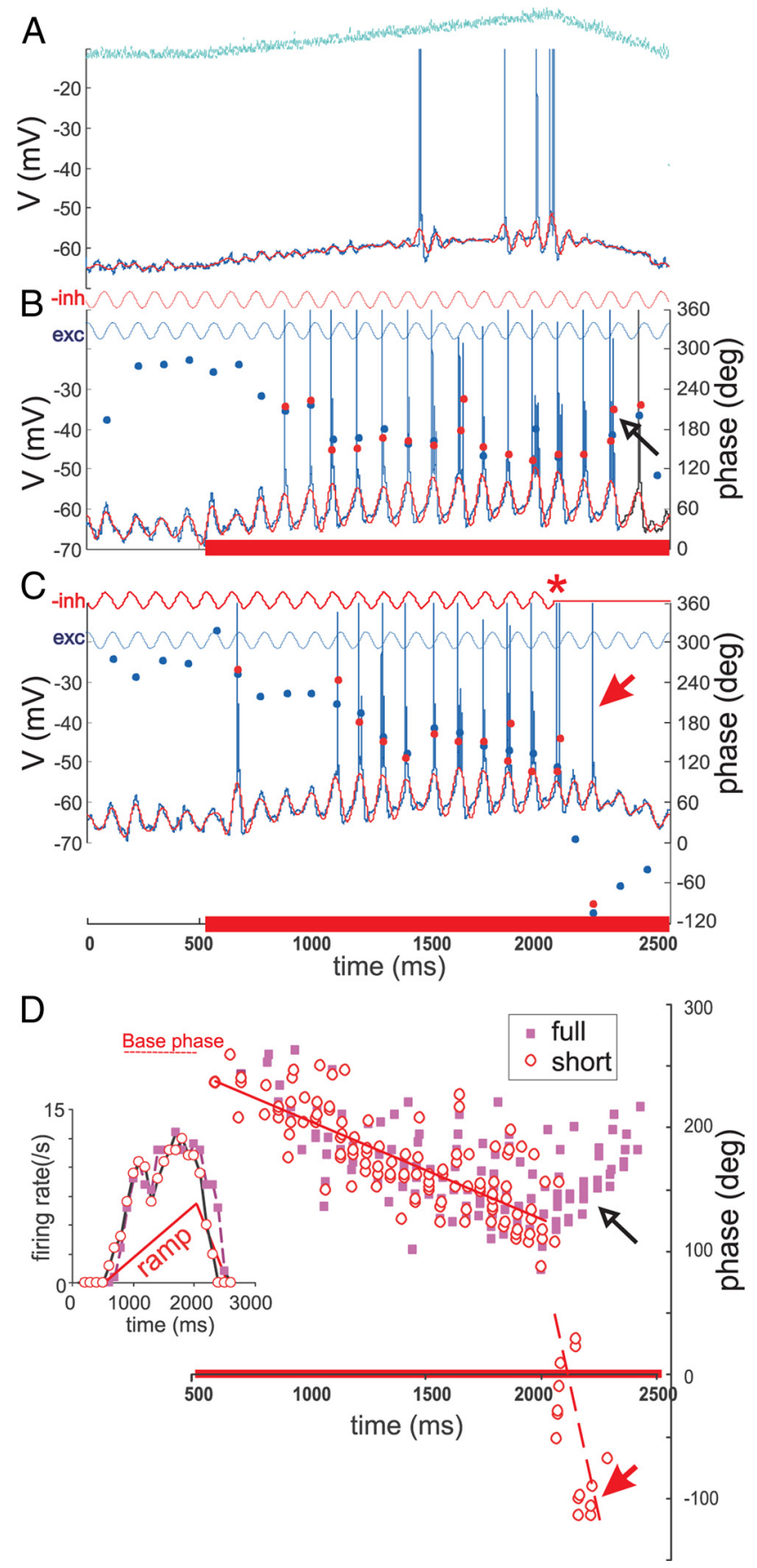

Figure 5. Early termination of inhibitory driving results in intrinsic oscillations and accelerated spike phase precession. $\boldsymbol{A}$, Membrane potential shows $\sim 13 \mathrm{~Hz}$ oscillations in response to $2048 \mathrm{~ms}$ duration depolarizing ramp alone, after a baseline of $512 \mathrm{~ms}$. $\boldsymbol{B}$, Depolarizing ramp with inhibitory and excitatory driving induce spike precession, which reverses (open arrow) at ramp repolarization. C, Early termination of inhibitory driving $\left(^{*}\right)$ at the peak of the depolarization ramp (time, $2048 \mathrm{~ms}$ ) allows natural oscillations ( $\sim 12$ $\mathrm{Hz}$ ) to emerge immediately after the asterisk $\left({ }^{*}\right)$, with spikes arising from the MPO peak (solid arrow). D, Group data for spike phase versus time with "full" duration (filled square symbols) and "short" (early terminated) inhibitory driving (unfilled circle symbols). Spike firing rates for both conditions are shown in inset; 10 simulations for each condition. Base phase indicates average phase of MPO peaks during baseline. Linear phase precession of spikes occur for both conditions during the rising phase of the depolarization ramp (solid red line; $\left.-80^{\circ} / \mathrm{s} ; R^{2}=0.61\right)$. After the depolarization peak, reversed phase precession for full duration driving (open arrow) does not happen with short duration driving which results in a faster phase precession (solid arrow) after the ramp peak at $>2048 \mathrm{~ms}$ (dotted red line; $\left.-852^{\circ} / s ; R^{2}=0.44\right)$. 

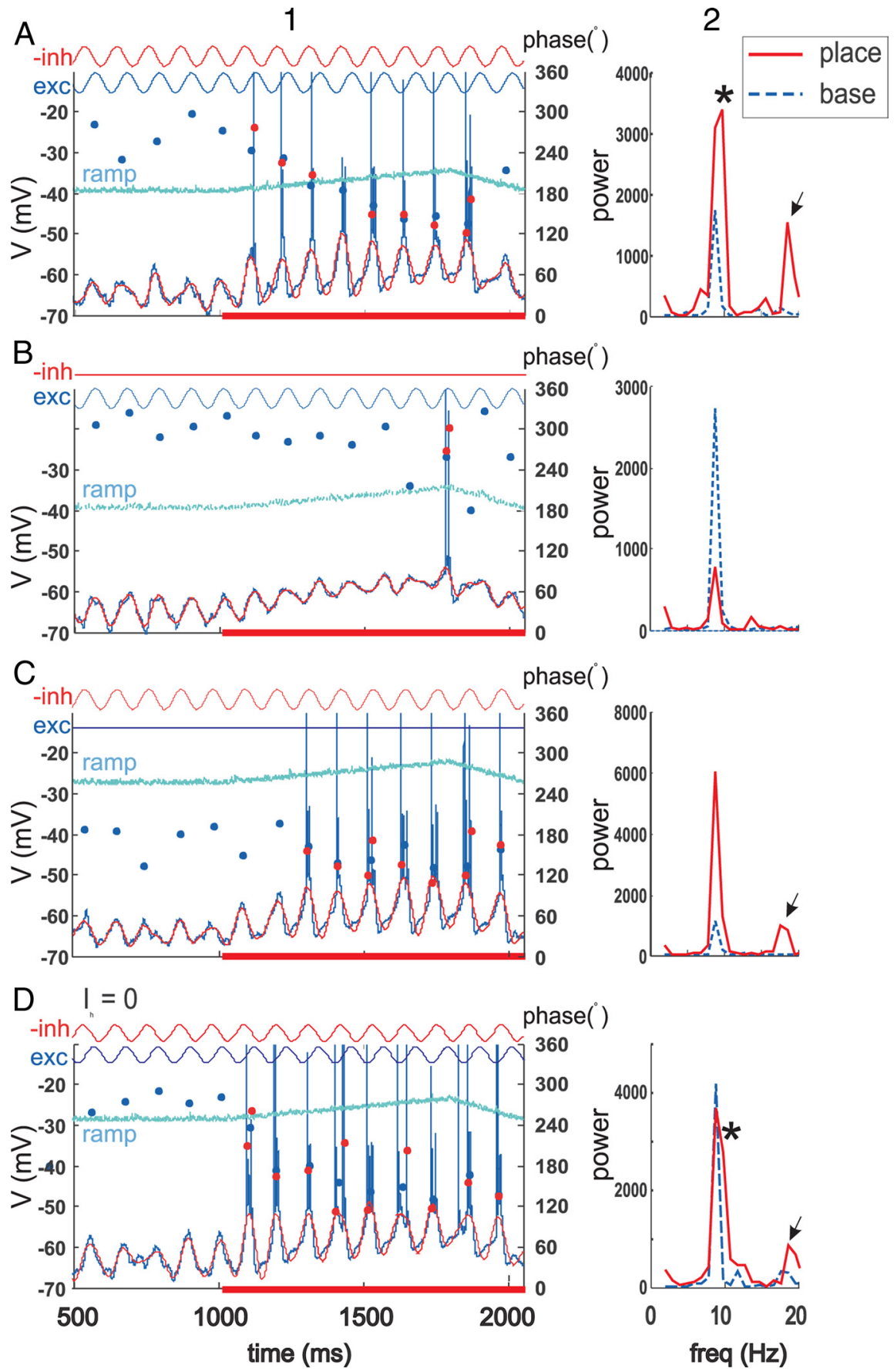

Figure 6. Inhibitory or excitatory rhythmic synaptic driving induces weak phase precession of the MPOs in the spiking model. Left column 1, Phase measures at the MPO peaks (filled circles) are plotted with the intracellular potential (lowest trace) and ramp/sinusoidal driving. Right column 2, Power spectrum of the MPOs in simulated place field ("place"; solid red trace), compared with that during baseline ("base"; dashed blue trace). $A$, MPO and spike precession are observed after combined excitatory and inhibitory driving, but much weaker after only excitatory (exc) driving (B), or only inhibitory (inh) driving (C). D, Same as $\boldsymbol{A}$ after combined excitatory and inhibitory driving but with $I_{\mathrm{h}}=0 ; \mathrm{MPO}$ power is increased, particularly during baseline. Column 1 shows an increase in power and frequency of MPOs in the place field in $\boldsymbol{A}$ and $\boldsymbol{D}\left({ }^{*}\right)$, and an increase in second harmonic of theta (arrow) in $A, C$, and $D$.

pared with combined excitatory and inhibitory driving (Fig. $6 \mathrm{~A}$, Table 3). Rhythmic excitation results in MPOs with decreased power/amplitude during the ramp depolarization (Fig. 6B2) compared with baseline. The latter is caused by a decrease in electromotive force of excitation (reversal potential, $0 \mathrm{mV}$; baseline resting potential, $-66 \mathrm{mV}$ ). Few spikes fire within the place field, and there is no significant spike phase precession when multiple simulations are grouped, or even when spike thresholds are decreased to allow for a higher firing rate.

When driven only by rhythmic inhibition, phase precession of MPOs and spikes in the place field is modest but consistently observed (Fig. 6C1, Table 3 ). The MPO amplitude and power increase during the depolarizing ramp (Fig. 6C2) because of an increase in the electromotive force of inhibition (reversal potential assumed for $\mathrm{Cl}^{-}$is $-72 \mathrm{mV}$ ) and intrinsic resonance (see below).

The phase precession of MPOs decreases slightly when the rhythmic modulation strength increases (Table 2). Driving frequency within $5-11 \mathrm{~Hz}$ results in similar theta phase precession in the place field, while driving at $13-15 \mathrm{~Hz}$ gives maximal MPO amplitudes but relatively lower phase precession during the second half of the place field (data not shown). The $9 \mathrm{~Hz}$ data presented are representative of the $5-11 \mathrm{~Hz}$ frequency range.

\section{Nature of the depolarizing ramp and rhythmic excitatory driving}

With a distal dendritic depolarizing ramp, which has been assumed for the above simulations, an increase in MPO frequency and power does not occur with rhythmic excitatory driving alone (Figs. $6 B, 7 A)$. Since both rhythmic excitatory driving and ramp act on the distal dendrites (compartments 35 and 36; Fig. $7 A 1$ ), and the excitatory electromotive force decreases with depolarization, a decreased response to rhythmic excitatory driving (Fig. 7A2,A3) during the ramp is observed. If the ramp inputs are shifted to excite the midapical dendrites (compartments 22 and 23), while keeping the average ramp depolarization at the soma the same, decreased response to rhythmic distal-dendritic driving in the place field is still apparent at the midapical compartments, but it is compensated by proximal resonant response such that the somatic MPOs are mainly unchanged in amplitude in the place field (Fig. $7 B$ ). More robust increase in somatic MPO amplitude in the place field occurs if the ramp is moved proximally, either becoming a depolarizing current at the soma (Fig. 7C) or a basal-dendritic excitation (data not shown). Voltage-dependent resonance in the place field is evidenced by a large increase in somatic MPO amplitude [Fig. 7C2, asterisk $\left(^{*}\right)$ ] and an increase in MPO frequency and power (Fig. 7C3). The somatic ramp alone, without rhythmic driving, induced intrinsic oscillations of $\sim 12 \mathrm{~Hz}$ (Fig. 7C2). 
High resonance models show MPO power increase and large

\section{phase precession}

Since $I_{\mathrm{NaP}}$ and $I_{\mathrm{KS}}$ have been implicated in theta-frequency resonance and MPOs (Introduction), different peak conductances of $I_{\mathrm{NaP}}$ and $I_{\mathrm{KS}}, G_{\mathrm{NaP}}$ and $G_{\mathrm{KS}}$, respectively, are simulated in subthreshold models. With the parameters presented for the normal $G_{\mathrm{NaP}}$ model above $\left(G_{\mathrm{NaP}}=\right.$ $\left.0.8 ; G_{\mathrm{KS}}=8\right)$, step current depolarization of the membrane to approximately -59 $\mathrm{mV}$ evoked a damped oscillation (Fig. $8 A 1$ ), characterized by a relatively sharp MPO power peak at $12 \mathrm{~Hz}$ (Fig. 8A2). The half-peak bandwidth (HBW) of the MPO power spectrum measures $7.5 \mathrm{~Hz}$, within the range of $\mathrm{HBW}$ determined experimentally by step or ZAP currents in CA1 pyramidal cells in vitro (Leung and Yim, 1991; Leung and Yu, 1998). Applying a swept-frequency sinusoidal current (ZAP function from 0 to $40 \mathrm{~Hz}$ ) at a mean membrane potential of $-59 \mathrm{mV}$ also yields a maximal impedance magnitude at $\sim 12$ $\mathrm{Hz}$ (Fig. 8A). Both magnitude and phase shift of the impedance are larger at -59 $\mathrm{mV}$ compared with $-67 \mathrm{mV}$ resting membrane potential (Fig. $8 A 2$, rest).

In a model with half normal $G_{\mathrm{NaP}}$ $\left(G_{\mathrm{NaP}}=0.4 ; G_{\mathrm{KS}}=8\right.$; Fig. $\left.8 B\right)$, step depolarization or ZAP current driving results in less rhythmic MPOs and low resonance, with a broad power peak at $\sim 16$ Hz. A model with zero $G_{\mathrm{NaP}}$ and $G_{\mathrm{KS}}$ shows no rhythmic response and no clear power peaks, with step or ZAP currents (Fig. $8 C$, zero $G_{\mathrm{NaP}}$ model). A high $G_{\mathrm{KS}}$ model $\left(G_{\mathrm{KS}}=24 ; G_{\mathrm{NaP}}=0.8\right.$; Fig. $\left.8 D\right)$ results in a broad response peak at 20-25 $\mathrm{Hz}$, using a step or ZAP current.

Somatic current-induced depolarizing ramp and proximal rhythmic inhibitory driving are used to study phase precession in the above models. Only subthreshold MPOs are illustrated. In a high-resonance model, strong phase precession occurs during the ramp, and a clear increase in MPO power and frequency is observed in the place field compared with baseline (Fig. 9A). Reducing $G_{\mathrm{NaP}}$ decreases resonance and the slope of phase precession in the place field (Fig. 9A-C, dashed linear regression line; Table 4, Inhibitory driving alone). However, MPO power in the place field is still higher than baseline in the zero $G_{\mathrm{NaP}}$ model (Fig. 9C2). The model with high $G_{\mathrm{KS}}$ shows a moderate phase precession and only a small MPO power increase in the place field (Fig. $9 D$ ). In the same models, driving by a rhythmic excitatory input generally yields a smaller phase precession than inhibitory drive, but a similar result that phase precession in the place field decreases with resonance of the model is observed (Table 4, Excitatory driving alone). No phase precession is found with purely excitatory diving in the zero $G_{\mathrm{NaP}}\left(\right.$ and zero $G_{\mathrm{KS}}$ ) model.

When normal spike thresholds are assumed in the above models, a brief $5 \mathrm{~ms}$ current induces a spike followed by afterpotentials of different shapes in different models (Fig. 8, column 1,
1

2

3
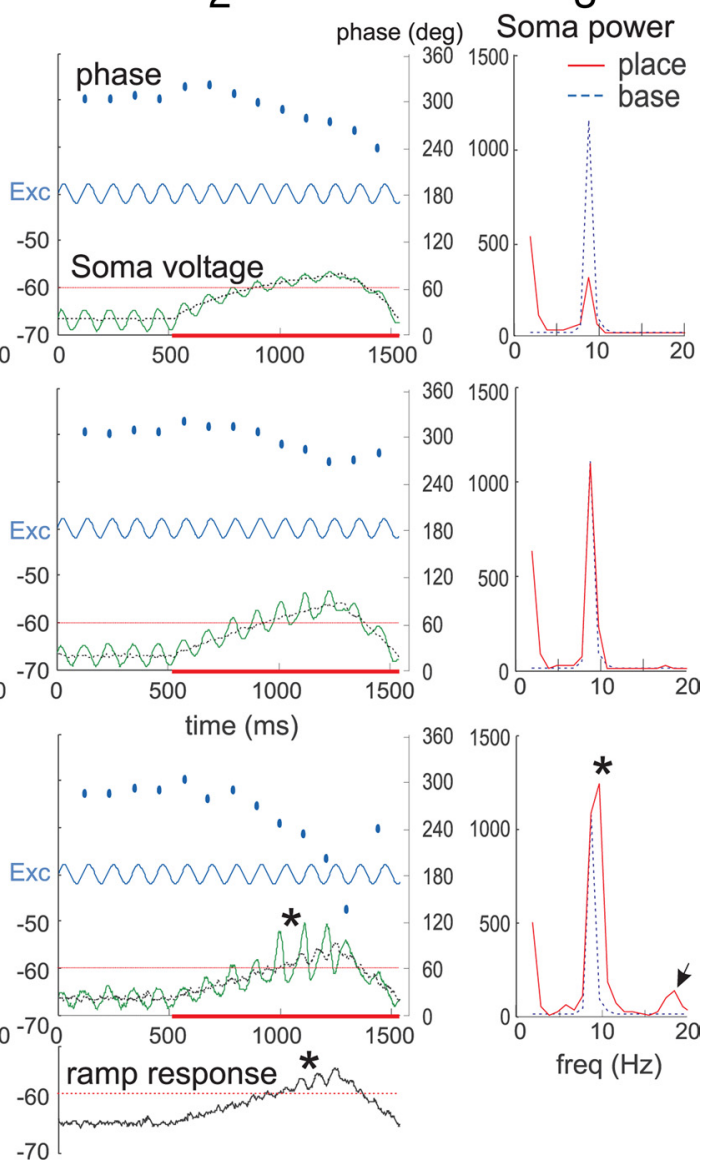

$-70$

Figure 7. Decrease of excitatory driving occurs during a depolarizing ramp. The location of depolarizing ramp changes from istal-dendritic excitation at compartments 35-36 (A), middendritic excitation at compartments 22-23 $(\boldsymbol{B})$, to depolarizing $(\mathrm{VNaA}=\mathrm{VNaD}=-28)$ for clarity. Column 1 shows voltage responses in different compartments of the model, 17 (soma), 23 harmonic in the place field $(\mathbf{C} 3$, arrow), compared with the baseline. Response to the somatic ramp only is reproduced below the time axis in $\mathbf{C}$, to highlight the intrinsic oscillations ( $\sim 12 \mathrm{~Hz}$ at $\left.{ }^{*}\right)$ induced by the ramp only.

spike trace). The normal $G_{\mathrm{NaP}}$ model (Fig. 8A1) has the largest depolarizing afterpotential (DAP), while the high $G_{\mathrm{Ks}}$ model (Fig. $8 \mathrm{D} 1$ ) has the largest afterhyperpolarization (AHP) of medium duration.

In separate simulations, it is shown that reduction or abolition of $I_{\mathrm{h}}$ has no effect on the phase precession of MPOs (Fig. $6 D$, Table 3 ), when a similar resting membrane potential is kept. Reduction of $I_{\mathrm{h}}$ increases input resistance and enhances dendritic inputs preferentially, giving larger MPO amplitudes, more so during baseline than in the place field (Fig. 6, compare $D$ with normal $I_{\mathrm{h}}$ responses in $A$ ). Similarly, $50 \%$ reduction of $I_{\mathrm{A}}$ or $I_{\mathrm{K}}$ increases input resistance but does not affect phase precession. The small phase precession found with inhibitory driving in the zero $G_{\mathrm{NaP}}$ model (Fig. 9C) can be partly attributed to voltage-dependent conductance of the $\mathrm{Na}^{+}$transient current. A small increase in MPO phase precession rate is shown with increasing spike rate, or decreasing spike threshold (Fig. 4E). 

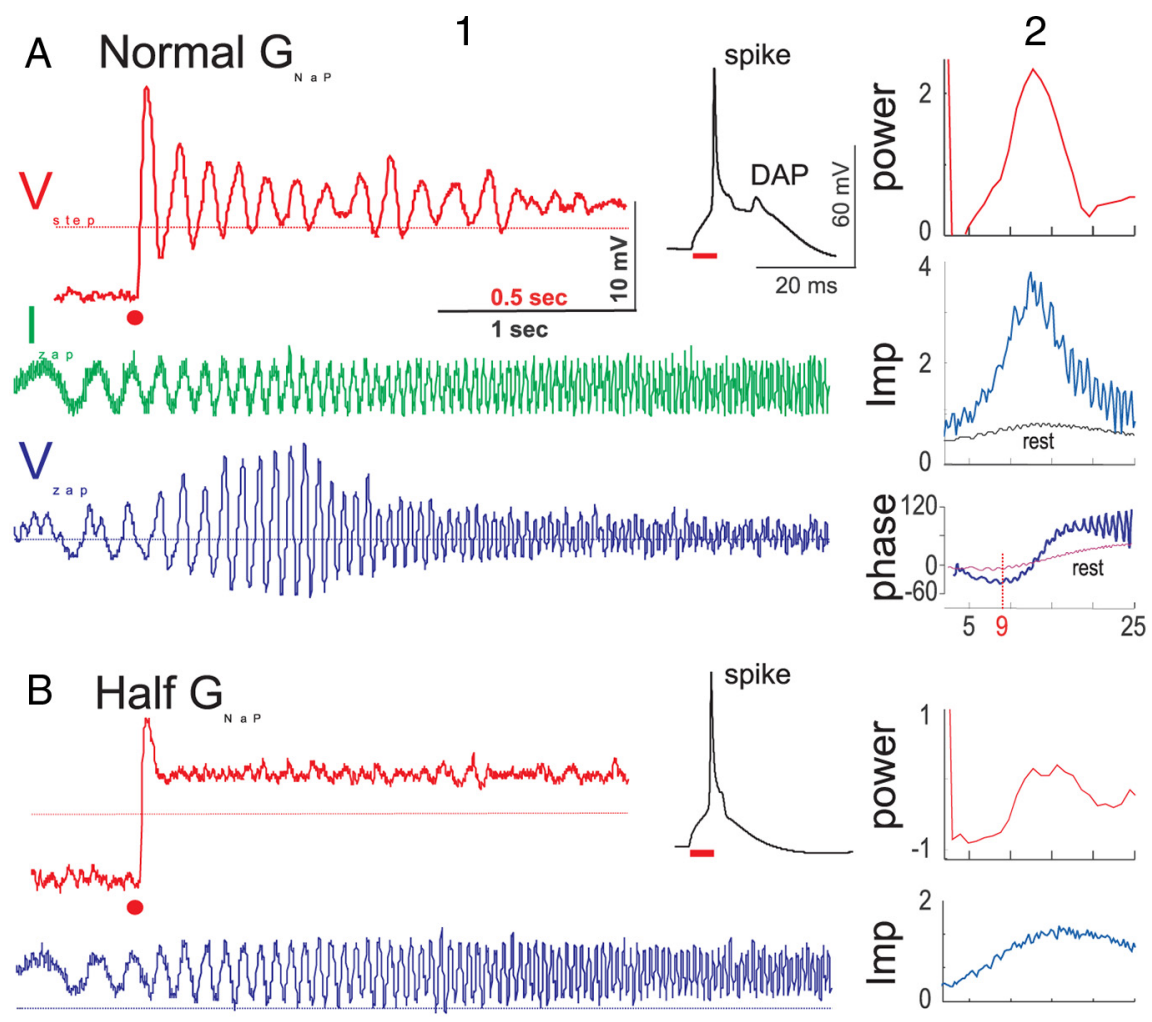

C Zero $G_{\text {Nap }}$
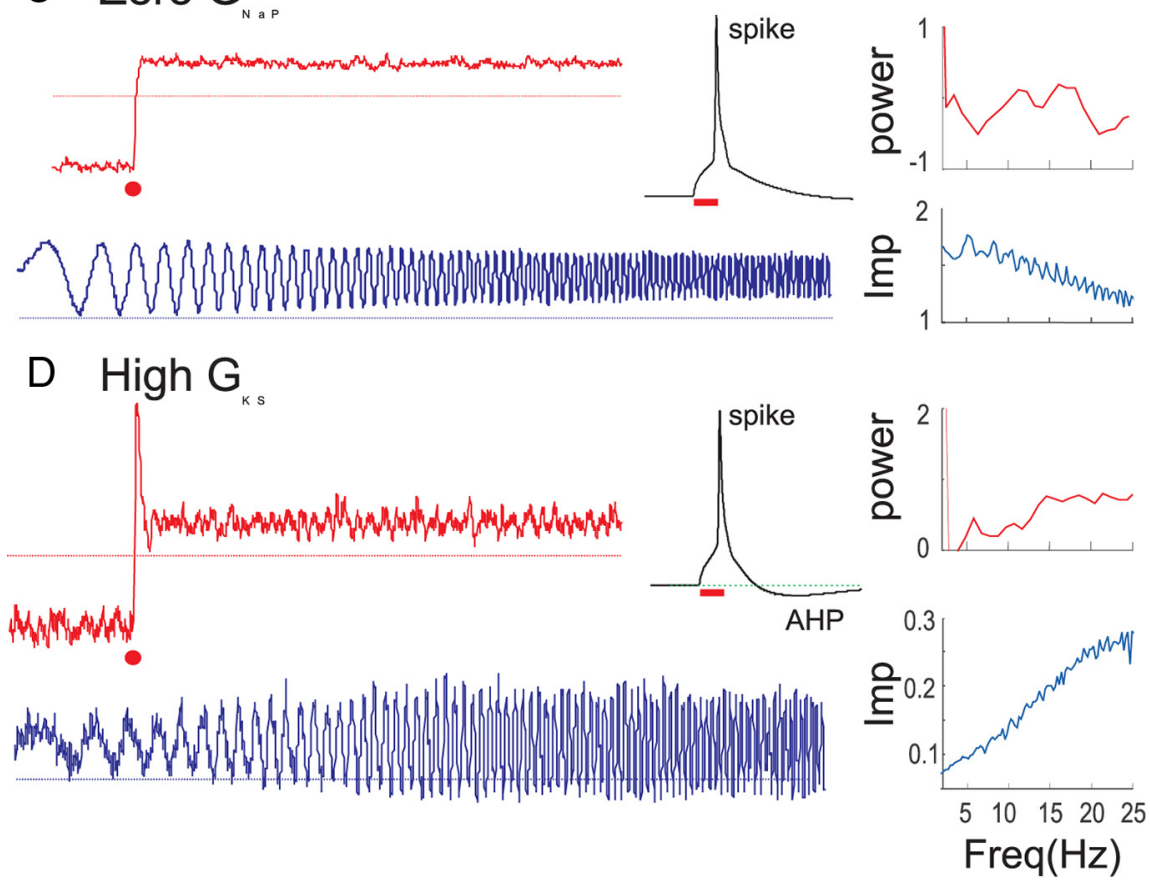

Figure 8. Subthreshold membrane potentials are induced by a step depolarizing current, or with current swept from 1 to $40 \mathrm{~Hz}$ $\left(I_{\text {zap }}\right.$ green trace) simulated in models with different conductances for persistent $\mathrm{Na}^{+}$current $\left(G_{\mathrm{NaP}}\right)$ and slowly inactivating $\mathrm{K}^{+}$ current $\left(G_{K S}\right)$. For all simulations, resting membrane potential ranges from -65 to $-66.5 \mathrm{mV}$. Column 1, The soma $\left(V_{\text {step }}\right.$; red traces) is depolarized $\sim 8 \mathrm{mV}$ by a step current (onset at red dot; horizontal dotted red line is $-60 \mathrm{mV}$ ), or induced to spike (black trace) by a 5 ms current (red line underneath spike trace). In another simulation, during the step current depolarization, a zap current $\left(I_{\text {zap }}\right.$, shown only in $\left.A\right)$ is applied, giving soma potential $V_{\text {zap }}$ (blue traces). Poisson's noise Exl $=0.2 * S A$ is added to the step and ZAP currents. Column 2, Logarithmic power spectrum of $V_{\text {step }}$ or impedance (Imp) spectrum estimated by $I_{\text {zap }}$. $\boldsymbol{A}$, Model with normal $G_{\mathrm{NaP}}=0.8, G_{\mathrm{KS}}=8$, in units of millisiemens per square centimeter, shows damped oscillation with current step, spike with depolarizing afterpotential (DAP), and a spectral peak at $\sim 12 \mathrm{~Hz}$ in both power and impedance; zap current amplitude $S A=2$ $\mu \mathrm{A} / \mathrm{cm}^{2}$. Imp and phase function estimated in column 2 during rest $(-65.5 \mathrm{mV})$ and steady depolarization $(-59 \mathrm{mV})$. $\boldsymbol{B}$, Model with one-half $G_{\mathrm{NaP}}(=0.4), G_{\mathrm{KS}}=8$ shows poorly rhythmic $V_{\text {step }}$ spike with small DAP, and broad power and impedance peaks; $S A=9$. C, Model with zero $G_{\mathrm{NaP}}\left(\right.$ also $\left.G_{\mathrm{KS}}=0\right)$ shows no detectable rhythm, no spike DAP, power or impedance peaks, $S A=5 . D$,
Phase precession explained by passive and active (voltage-dependent) processes

Phase precession in the place field is attributed to both passive and active mechanisms. The passive mechanism occurs as a change in balance between excitatory and inhibitory drives (e.g., simulated in Figs. 2 and 6). During the baseline, the phase in response to a pure inhibitory drive (with respect to the peak of the inhibitory conductance) is $\sim 180^{\circ}$ (hyperpolarization is a negative response; Fig. $6 C)$, and the phase in response to a pure excitatory drive is $\sim 300^{\circ}$ (Fig. $6 \mathrm{~B}$ ). The resultant vector $\left(\mathbf{R}_{\mathbf{1}}\right)$, at resting membrane potential of $-67 \mathrm{mV}$, is approximated by the vector sum of the inhibitory response (vector $\mathbf{I}_{1}$ ) and the excitatory response (vector $\mathbf{E}_{1}$; Fig. $10 A$ ). In the place field, where the depolarizing ramp is assumed to peak at $-52.7 \mathrm{mV}$, the excitatory response $\left(\mathbf{E}_{2}\right)$ decreases by approximately one-half, because of a decrease in electromotive force and nonlinear shunting (Fig. $7 A 2)$, while the inhibitory response $\left(\mathbf{I}_{2}\right)$ increases approximately sevenfold because of an increase in electromotive force. The resultant vector $\mathbf{R}_{\mathbf{2}}$ in the place field thus shifts toward $\mathbf{I}_{2}$, a decrease in phase by $87^{\circ}$ from $\mathbf{R}_{\mathbf{1}}$.

Phase and amplitude change also occurs because of active resonance, contributed by a voltage-dependent intrinsic mechanism. The steady-state phase lag in response to a constant $9 \mathrm{~Hz}$ driving current is $-6.3^{\circ}$ during baseline $(-67 \mathrm{mV})$, and $-50.7^{\circ}$ at the peak of the depolarization ramp (Fig. $10 \mathrm{~B}$, inset), as determined using sweptfrequency current (Fig. $8 \mathrm{~A}$ ). This voltagedependent phase shift occurs with an excitatory drive, resulting in a negative $44^{\circ}$ phase shift of $\mathbf{E}_{2}$ with respect to $\mathbf{E}_{\mathbf{1}}$ (Fig. $10 \mathrm{~B})$. Similarly, $\mathbf{I}_{2}$ is shifted $-44^{\circ}$ from $\mathbf{I}_{1}$ (Fig. $10 \mathrm{~B}$ ), and the resultant vector (sum of $\mathbf{E}$ and I vectors) is also $-44^{\circ}$ shifted from that during baseline (data not shown). The active resonance contributes an additional $44^{\circ}$ to the passive condition (which gives $87^{\circ}$ ), resulting in a $132^{\circ}$ shift of $\mathbf{R}_{2}$ with respect to $\mathbf{R}_{\mathbf{1}}$ (Fig. 10C). Phase change because of self-sustaining intrinsic oscillations (Figs. 5A, $C, 7 C 2$ ) has not been included in Figure 10. The latter phase precession is caused by having an intrinsic oscillation of higher frequency than the reference theta signal ( $9 \mathrm{~Hz}$ assumed above).
Model of high $G_{\mathrm{KS}}(=24)$ and $G_{\mathrm{NaP}}=0.8$ shows no thetafrequency rhythms, spike with large afterhyperpolarization (AHP), and broad power/impedance peaks at $20-25 \mathrm{~Hz}, \mathrm{SA}=18$. 
1

A Normal $G_{n a p}$
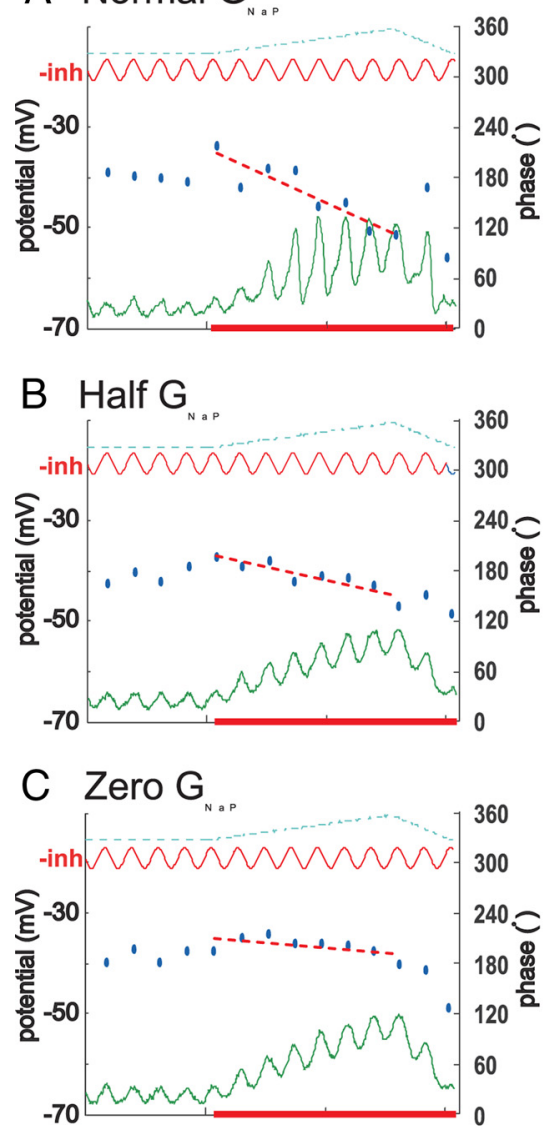

D High $G_{k s}$

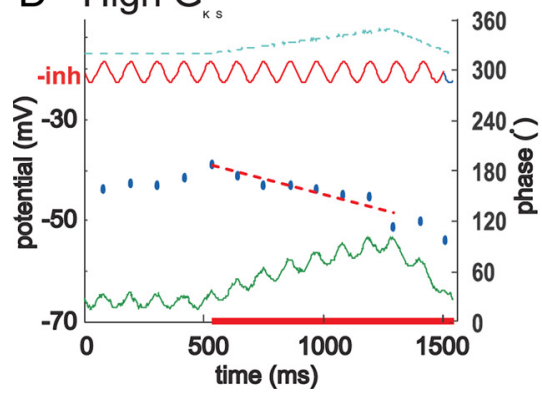

2
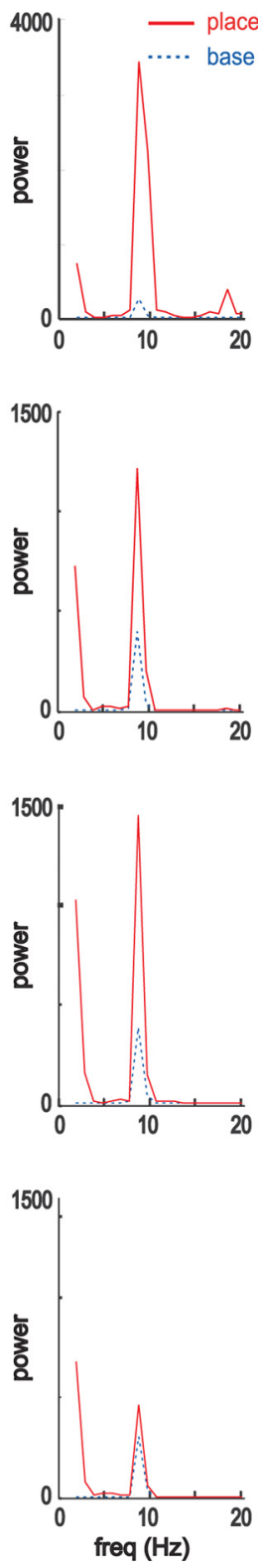

Figure 9. Models with strong resonance show stronger phase precession of the subthreshold MPOs. Somatic voltage (column 1) and power spectra in place field and baseline (column 2) are shown. Rhythmic inhibitory drive is given with a depolarizing somatic ramp current; resting membrane potential and average ramp depolarization are kept within $1 \mathrm{mV}$ among the different models (Table 4). The four versions of the model in this figure corresponds to $\boldsymbol{A}-\boldsymbol{D}$ of Figure 8 , with normal $G_{\text {NaP, }}$, high-resonance model showing an increase in MPO amplitude and frequency, and MPO phase precession $(\boldsymbol{A})$, and models with little or no theta-frequency resonance showing no increase in MPO amplitude or frequency during the ramp, and a modest phase precession in some cases $(\boldsymbol{B}-\boldsymbol{D})$.

\section{Single-compartment model of phase precession}

To show that the main properties of phase precession of a resonant neuron are not related to an interaction between soma and dendrites and the multiple parameters of the model, simulations are made in a one-compartment model. The latter is the soma compartment of the 38-compartment model, which now also receives a rhythmic excitatory synaptic drive, in addition to the rhythmic inhibitory drive and a somatic current ramp in the following simulation.
Table 4. Phase precession of subthreshold MPOs during a somatic injected depolarizing current ramp of $1024 \mathrm{~ms}$, driven by either rhythmic excitatory or rhythmic inhibitory input at $9 \mathrm{~Hz}$

\begin{tabular}{|c|c|c|c|c|c|c|c|c|}
\hline$G_{\mathrm{NaP}}$ & $G_{\mathrm{KS}}$ & Si & $\mathrm{Se}$ & $\begin{array}{l}\text { Reg line } \\
\text { slope }(\% / s)\end{array}$ & $R^{2}$ & $\begin{array}{l}\text { Base } \\
\text { power }\end{array}$ & $\begin{array}{l}\text { Place } \\
\text { power }\end{array}$ & $\begin{array}{l}\text { Power } \\
\text { ratio }\end{array}$ \\
\hline \multicolumn{9}{|c|}{ Inhibitory driving alone } \\
\hline 0.8 & 8 & 0.3 & 0 & -130 & 0.83 & 347 & 6064 & 17 \\
\hline 0.4 & 8 & 0.4 & 0 & -63 & 0.82 & 449 & 1527 & 3.4 \\
\hline 0 & 0 & 0.4 & 0 & -25 & 0.36 & 462 & 1694 & 3.7 \\
\hline 0.8 & 24 & 0.5 & 0 & -68 & 0.78 & 358 & 620 & 1.7 \\
\hline \multicolumn{9}{|c|}{ Excitatory driving alone } \\
\hline 0.8 & 8 & 0 & 0.1 & -89 & 0.69 & 1368 & 3716 & 2.7 \\
\hline 0.4 & 8 & 0 & 0.13 & -53 & 0.56 & 1295 & 829 & 0.64 \\
\hline 0 & 0 & 0 & 0.1 & 0 & 0 & 1444 & 753 & 0.52 \\
\hline 0.8 & 24 & 0 & 0.25 & -68 & 0.62 & 1335 & 615 & 0.46 \\
\hline
\end{tabular}

For all models, resting membrane potential is -65 to $-66 \mathrm{mV}$, and average depolarization during ramp is -59 to $-60 \mathrm{mV}$. Driving amplitude is adjusted to give similar baseline power across models. All parameters are defined as in Table 2.

The single-compartment model with no $G_{\mathrm{NaP}}$ conductance $\left(G_{\mathrm{NaP}}=G_{\mathrm{KS}}=0\right)$ shows no subthreshold resonance when driven by a ZAP function at a steady-state resting membrane potential of $-58.7 \mathrm{mV}$ (Fig. $11 A 3, B$ ). Adding $G_{\mathrm{NaP}}=0.1$ (and $G_{\mathrm{KS}}=1$ ) conductance bestows a peak response at $\sim 11 \mathrm{~Hz}$ and half-peak bandwidth of $16 \mathrm{~Hz}$ (Fig. $11 \mathrm{~B}$ ). When combined rhythmic excitatory and inhibitory inputs are given to the $G_{\mathrm{NaP}}=0.1$ model with a high spike threshold $(\mathrm{VNaD}=-32)$ assumed, gradual phase precession appears soon after the onset of an excitatory ramp (Fig. 11C), and the phase decreases during the depolarizing phase of the ramp. The phase precession of the MPOs remains similar when a normal spike threshold $(V \mathrm{NaD}=-35)$ is assumed (Fig. 11C2). The phase decrease within the place field occurs with different run durations, as shown in the plot of phase versus normalized field duration (Fig. 11D). Similar to the 38-compartment model, the magnitude of the average phase precession slope for the MPO peaks is only weakly dependent on duration (Fig. 11E). Spikes ride on top of the MPO peaks, and the linearly fitted phase precession slope of spikes is larger than that for MPO peaks (Fig. $11 \mathrm{E}$; also apparent in C2).

The one-compartment model (Fig. 11C) shows a large increase in MPO amplitude with ramp depolarization in the place field, similar to that during a somatic ramp in the 38compartment model (Fig. 7C). Impedance spectrum of a single compartment (Fig. $11 B$ ) is similar to that of the 38-compartment model (Fig. $8 \mathrm{~A}$ ). However, the single compartment model shows a smaller rate of MPO phase precession, and a smaller total phase decrease in the place field compared with the 38-compartment model (Fig. 11D).

\section{Discussion}

\section{Space coding and theta-frequency oscillation}

This report illustrates how oscillations can be used to generate neural coding of absolute space (Figs. 2D, 4D, 11D). A spatial signal is coded by a depolarization ramp, and the transduction of this depolarization into a phase code depends on an external oscillator serving as a phase reference as well as a driving input and intrinsic membrane properties. A phase code for MPO is directly related to a phase code for spiking, since spikes tend to fire at the MPO peaks, in support of the notion that precession of MPOs is the cause of spike precession (Harvey et al., 2009).

Like most reliable coding, the present phase code has a considerable safety margin. Phase precession of the MPO peaks is only briefly affected by single-pulse afferent-evoked excitation 


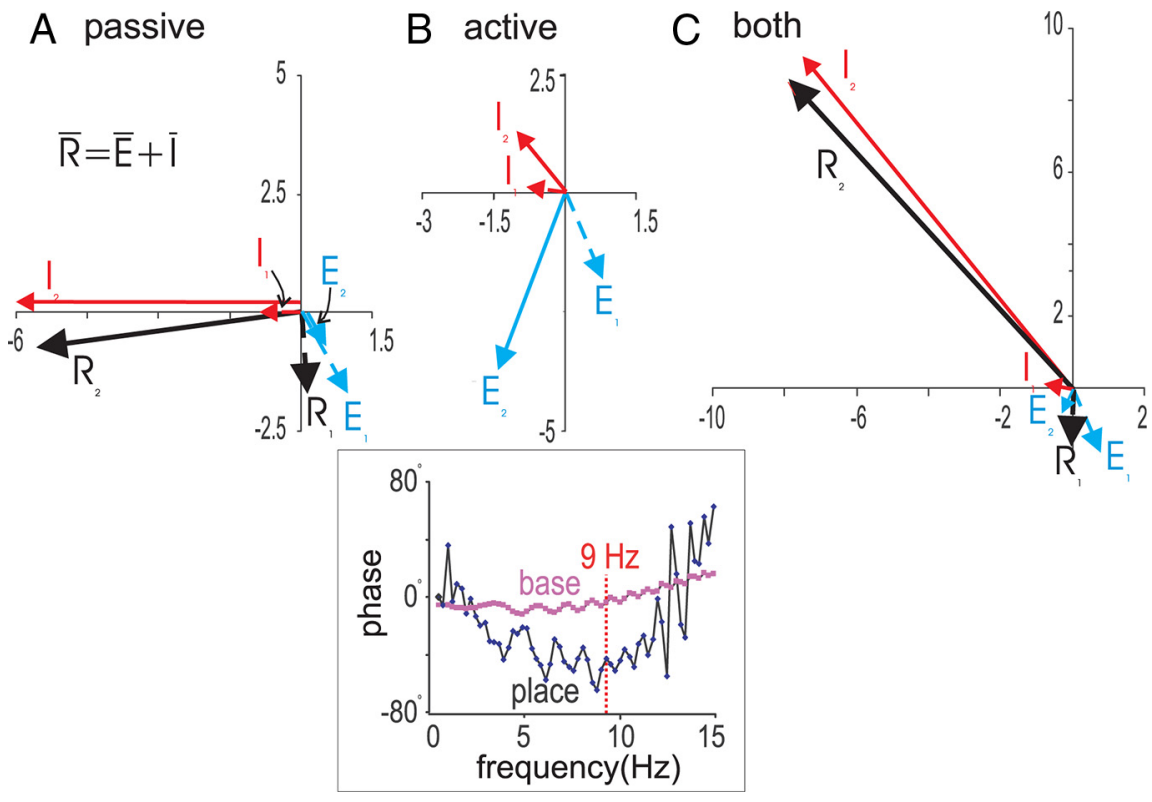

Figure 10. Explanation of phase precession by passive and active mechanisms. Phase plane diagram of amplitude (in millivolts) and phase change of the inhibitory response (I), excitatory response (E), and their resultant (R) vector, during baseline (resting, $-67 \mathrm{mV}$; vector subscript 1 ) and peak depolarization in place field ( $-52.7 \mathrm{mV}$; vector subscript 2 ). $A$, Passive condition, excitatory driving during baseline $\left(\mathbf{E}_{1}\right)$ is assumed to be $300^{\circ}$, while $\mathbf{I}_{1}$ response is $180^{\circ}$. Change in electromotive force in the place field increases inhibitory response and decreases excitatory response, resulting in $87^{\circ}$ phase shift of $\mathbf{R}_{\mathbf{2}}$ from $\mathbf{R}_{\mathbf{1}}, \boldsymbol{B}$, Active condition with a voltage-dependent impedance and constant current driving (without change in electromotive force); either excitatory or inhibitory response is increased in amplitude and phase shifted by $44^{\circ}$. The bottom inset illustrates the phase plotted with frequency at rest (baseline) and in the place field, measured using ZAP functions (Fig. 8A). C, Combined condition approximated by linear summation of passive and active responses, resultant vector phase change is $132^{\circ}$.

and inhibition (Fig. 3). It can occur with rhythmic excitatory or/and inhibitory driving of different modulation depths. Phase precession results from different mechanisms induced by the depolarization ramp. The first is a passive phase change caused by a shift in the relative strengths of the excitatory and inhibitory responses (Fig. 10A). The second is an active theta-frequency resonance that mainly depends on the interaction between slow voltage-dependent $\mathrm{Na}^{+}$and $\mathrm{K}^{+}$currents (Fig. $10 \mathrm{~B}$ ). The third is a nonlinear interaction of driven and intrinsic oscillations; intrinsic oscillations can be induced by a moderate depolarization of approximately $-60 \mathrm{mV}$ alone (Figs. 5A, 7C2). Other than generating phase precession, the active voltage-dependent mechanisms are critical to MPO frequency increase and a second harmonic in the place field (Figs. 6, 9A).

Phase precession of the order of $180^{\circ}$, consistent with the spike phase precession after a single run through the place field (Schmidt et al., 2009), are simulated by passive and resonance mechanisms in the present report. Larger phase precession of $180-360^{\circ}$ (O'Keefe and Recce, 1993; Skaggs et al., 1996) may require activation of intrinsic oscillations (Figs. $5 C, D, 7 C 2$ ). A small reversal of phase precession is found at the end of a longduration simulated run through the place field (Figs. $2 D, 5 B$; but see Figs. $2 A, 7 A 2$ ). Whether this small phase reversal of the MPOs occurs in vivo is not known, but spikes were reported to continue their phase precession despite decreasing firing rate (Huxter et al., 2003). Factors such as spike accommodation will suppress spiking during ramp repolarization (Harris et al., 2002), and cessation of inhibitory driving and release of intrinsic oscillations will maintain continuous spike phase precession (Fig. 5C).

Either excitatory or inhibitory rhythmic driving can result in phase precession in the place field during a depolarizing ramp. With a distal dendritic depolarization ramp, a rhythmic inhibitory drive typically gives stronger phase precession than a rhythmic excitatory drive. This is explained by a depolarizationinduced increase in driving current for an inhibitory, but not an excitatory drive. An increase in rhythmic driving increases peak depolarization and gives stronger phase precession via a voltagedependent mechanism.

Two membrane currents- $I_{\mathrm{NaP}}$ and $I_{\mathrm{KS}}$ - particularly contribute to intrinsic phase precession. Interaction between $I_{\mathrm{NaP}}$ and $I_{\mathrm{KS}}$ has been shown to result in oscillatory response in other studies (Gutfreund et al., 1995; White et al., 1995; Golomb et al., 2006; Prescott and Sejnowski, 2008). In CA1 pyramidal cells in vitro, theta-frequency resonance at a depolarized voltage depended on both $I_{\mathrm{NaP}}$ and $I_{\mathrm{M}}$ (Hu et al., 2002, 2007), and lowthreshold subthreshold theta-frequency MPOs were suppressed when $I_{\mathrm{NaP}}$ was blocked (Leung and Yim, 1991). $I_{\mathrm{NaP}}$ contributes to the depolarizing afterpotential (Yue et al., 2005), as shown by the simulated action potential (Fig. 8), and the present study suggests that neurons with different $I_{\mathrm{NaP}}$ to $I_{\mathrm{KS}}$ ratio may show different phase precession rate (Fig. 9). The present report further predicts that phase precession of theta-frequency MPOs will be reduced when $I_{\mathrm{NaP}}$ or $I_{\mathrm{M}}$ is blocked. Blockade of $I_{\mathrm{h}}$ in CA1 pyramidal cells did not affect MPOs (Leung and Yim, 1991) or proximal resonance (Hu et al., 2002), and the present model suggests that $I_{\mathrm{h}}$ blockade increases MPO amplitudes but does not affect phase precession (Fig. 6D). Nolan et al. (2004) reported larger theta field potentials in $I_{\mathrm{h}}$-knock-out mice, but theta phase precession was not studied.

\section{Properties of the external inputs}

Two types of external inputs - a depolarization ramp and a rhythmic synaptic input-are assumed. The simulations here do not predict a location for the depolarizing ramp, but they elucidate the consequences of proximal versus distal ramp depolarization. A distal dendritic ramp would suppress rhythmic excitation and increase passive phase precession during combined excitatory-inhibitory driving, since a decrease of excitatory strength will shift the resultant phase more toward the inhibitory vector (Fig. $10 \mathrm{~A}$ ). However, for a fixed current, proximal rather than distal ramp causes a larger depolarization that activates stronger active currents, including $I_{\mathrm{NaP}}$ and $I_{\mathrm{M}}$, thus giving stronger voltagedependent phase precession (Fig. 7). As distinct from models in which a depolarizing ramp serves to decrease spike latency (Magee, 2001; Harris et al., 2002; Mehta et al., 2002), the ramp in the present model decreases the period of the MPOs. Since the entorhinal cortex codes for spatial information (Hafting et al., 2005), a distal apical dendritic ramp excitation of CA1 from the entorhinal cortex (Witter, 2007) appears to be more realistic for place coding. Furthermore, other studies suggest that place coding does not require the integrity of CA3 (Brun et al., 2002, 2008). However, during recall, CA3 may be necessary (Wallenstein and 
Hasselmo, 1997), and CA3 pyramidal cells may provide a ramp excitation of CA1 pyramidal cells at the midapical dendritic synapses (Amaral and Lavenex, 2007; Witter, 2007).

In studies in vivo, injection of current at the soma did not induce MPOs in CA1 neurons of awake mice (Harvey et al., 2009) or affect the phase of MPOs of CA1 neurons during a theta rhythm (of $\sim 4$ $\mathrm{Hz}$ ) in urethane-anesthetized rats (Bland et al., 2002). It is possible that the conditions during which currents were injected are different from those present within the place field [e.g., lack of $I_{\mathrm{M}}$ modulation (below) or nonoptimal theta frequency].

\section{Comparison with previous models}

Phase precession, frequency, and power increase of the subthreshold MPOs were intracellular signatures of place cells (Harvey et al., 2009). The present report emphasizes that an intrinsic voltagedependent mechanism contributes to these signatures. Two recent reports suggest that network models can also account for the intracellular MPO results, as shown in a CA3 network model (Romani et al., 2010) and a nonlinear recurrent network of CA1 neurons (Jayet Bray et al., 2010). Given the different types of neurons that demonstrate theta activity (Bland and Colom, 1993; Buzsáki, 2002) and phase precession (Moser et al., 2008) in the hippocampal formation, including neurons in the dentate gyrus, CA3, and entorhinal cortex, it is likely that more than one mechanism contributes to phase precession. The strength of the present model lies in its close ties with physiological data, and the ability to experimentally test the model by manipulating intrinsic membrane properties of a single CA1 cell.

Interference among two or more independent frequency sources can result in phase precession in hippocampal place cells (Burgess and O'Keefe, 1996; Lengyel et al., 2003) and entorhinal grid cells (Burgess et al., 2007; Hasselmo, 2008). In particular, phase precession in place cells is proposed to result from interference of independent somatic and dendritic oscillations of different frequencies. In the present model, an independent somatic oscillation may be generated by an intrinsic voltage-dependent mechanism involving slowly inactivating, proximal $\mathrm{Na}^{+}$and $\mathrm{K}^{+}$ currents that are activated by a small depolarization (Leung and Yim, 1991; Hu et al., 2002, 2007). No dendritic oscillations have been included in the present model because they require large depolarization (greater than $-50 \mathrm{mV}$ ) to activate in vitro (Leung and Yim, 1991) or in vivo (Kamondi et al., 1998). A crucial difference between the present model and previous linear interference models is that intrinsic resonance/oscillations are voltage dependent and not manifested outside of the place field. Thus, there are no off-field oscilla-
B
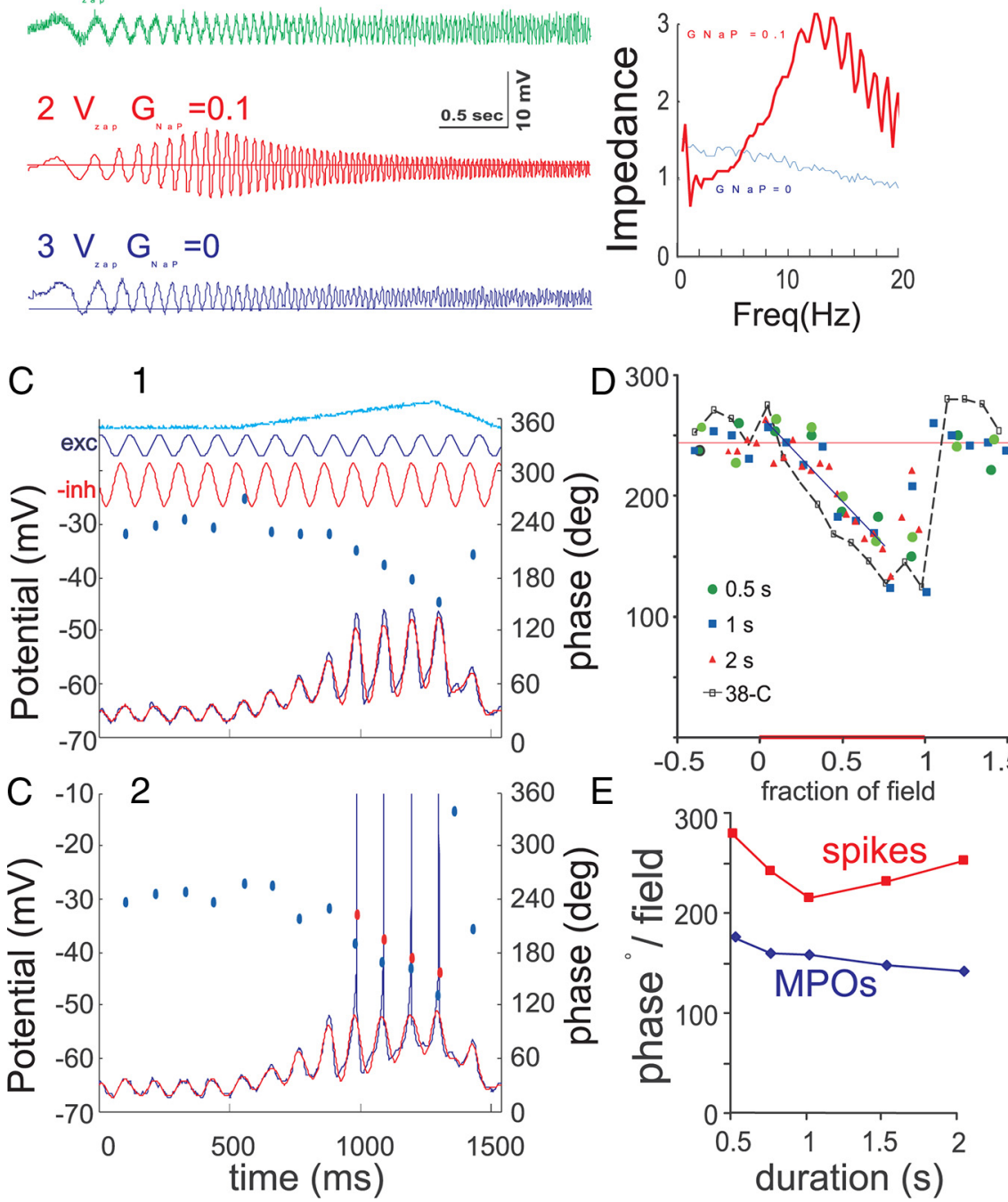

Figure 11. One-compartment model shows run duration-independent phase precession in the place field. $A$, Voltage response $(V)$ to a swept-frequency sinusoidal current $\left(I_{\text {zap }}\right.$ in row 1$)$, in resonant model with normal $G_{\mathrm{NaP}}=0.1$ and $G_{\mathrm{KS}}=1$ in row 2 , and model with $G_{\mathrm{NaP}}=G_{\mathrm{KS}}=0$ (row 3); in each case, steady-state depolarizing current maintains depolarization near $-60 \mathrm{mV}$ (dotted horizontal line). $\boldsymbol{B}$, Impedance (voltage/current) as a function of frequency showing resonance with normal $G_{\mathrm{NaP}}$ model when depolarized to $-59.8 \mathrm{mV}$ (half-peak bandwidth, $\sim 16 \mathrm{~Hz}$ ), and no resonance in zero $G_{\mathrm{NaP}}$ model. $\boldsymbol{C}$, Representative time $0.04)$ inputs. An excitatory ramp $(\mathrm{RpG}=0.05)$ depolarizes the membrane to an average of $-59.8 \mathrm{mV}$ during the ramp is assumed during the place field, and either subthreshold $(\mathrm{VNa}=-32 ; \mathrm{C})$ or normal spike threshold $\left(\mathrm{VNaD}=-35 \mathrm{mV}, V_{\text {noise }}=0, G_{\mathrm{DR}} / C_{1}=\right.$ of the place field shows similar phase precession for runs of three different durations $(0.5,1$, and $2.048 \mathrm{~s})$, but slightly lower than that of the 38-compartment model (38-C; symbols with connected dashed line). $\boldsymbol{E}$, Magnitude of linear regression slope of MPO peaks and spikes during the depolarizing phase of the ramp ( $\%$ field) plotted with the duration of run through the place field; all slopes have linear fit of $R^{2}>0.8$. The slope of phase precession is larger for spikes than for MPO peaks, and both slopes show $<25 \%$ change in magnitude with fourfold change in run duration.

tions as in a linear interference model (Burgess and O'Keefe, 1996). The contribution of intrinsic resonance/oscillations to MPO phase precession is not included in another somatic-dendritic interaction model (Losonczy et al., 2010).

Hippocampal activation may be needed for optimal coding of space through phase precession. A movement-related theta rhythm indicates hippocampal activation by the medial septum and brainstem (Vanderwolf, 1988; Lee et al., 1994; Leung, 1998; Bland, 2000; Buzsáki, 2002), which involves cholinergic, GABAergic, and glutamatergic afferents (Amaral and Lavenex, 2007). Septal inputs may increase excitability and spiking, as well as modulate subsequent response through intracellular signaling (Krnjević, 1993; Leung and 
Peloquin, 2010). In particular, muscarinic cholinergic modulation may decrease various $\mathrm{K}^{+}$conductances in the hippocampus (Krnjević, 1993), including $I_{\mathrm{M}}$, and increase theta-frequency resonance. It is known that place field firing was disrupted by blockade of muscarinic cholinergic receptors (Brazhnik et al., 2004).

In conclusion, it is shown that rhythmic synaptic driving, with the appropriate intrinsic membrane properties, results in robust phase precession of the subthreshold MPOs. An increase in the amplitude (power) and frequency of the subthreshold MPOs in the place field is simulated.

\section{References}

Alonso A, Llinás RR (1989) Subthreshold $\mathrm{Na}^{+}$-dependent theta-like rhythmicity in stellate cells of entorhinal cortex layer II. Nature 342:175-177.

Amaral D, Lavenex P (2007) Hippocampal neuroanatomy. In: The hippocampus book (Andersen P, Morris R, Amaral D, Bliss T, O'Keefe J, eds), pp 37-114. Oxford: Oxford UP.

Bland BH (2000) The medial septum: the node of the ascending brainstem hippocampal synchronizing pathways. In: The behavioural neuroscience of the septal region (Numan R, ed), pp 115-145. New York: Springer.

Bland BH, Colom LV (1993) Extrinsic and intrinsic properties underlying oscillation and synchrony in limbic cortex. Prog Neurobiol 41:157-208.

Bland BH, Konopacki J, Dyck RH (2002) Relationship between membrane potential oscillations and rhythmic discharges in identified hippocampal theta-related cells. J Neurophysiol 88:3046-3066.

Bose A, Recce M (2001) Phase precession and phase-locking of hippocampal pyramidal cells. Hippocampus 11:204-215.

Brazhnik E, Borgnis R, Muller RU, Fox SE (2004) The effects on place cells of local scopolamine dialysis are mimicked by a mixture of two specific muscarinic antagonists. J Neurosci 24:9313-9323.

Brun VH, Otnass MK, Molden S, Steffenach HA, Witter MP, Moser MB, Moser EI (2002) Place cells and place recognition maintained by direct entorhinal-hippocampal circuitry. Science 296:2243-2246.

Brun VH, Leutgeb S, Wu HQ, Schwarcz R, Witter MP, Moser EI, Moser MB (2008) Impaired spatial representation in CAl after lesion of direct input from entorhinal cortex. Neuron 57:290-302.

Burgess N, O'Keefe J (1996) Neuronal computations underlying the firing of place cells and their role in navigation. Hippocampus 6:749-762.

Burgess N, Barry C, O'Keefe J (2007) An oscillatory interference model of grid cell firing. Hippocampus 17:801-812.

Buzsáki G (2002) Theta oscillations in the hippocampus. Neuron $33: 325-340$

Fox SE (1989) Membrane potential and impedance changes in hippocampal pyramidal cells during theta rhythm. Exp Brain Res 77:283-294.

French CR, Sah P, Buckett KJ, Gage PW (1990) A voltage-dependent persistent sodium current in mammalian hippocampal neurons. J Gen Physiol 95:1139-1157.

Gasparini S, Migliore M, Magee JC (2004) On the initiation and propagation of dendritic spikes in CA1 pyramidal neurons. J Neurosci 24:11046-11056.

Geisler C, Robbe D, Zugaro M, Sirota A, Buzsáki G (2007) Hippocampal place cell assemblies are speed-controlled oscillators. Proc Natl Acad Sci U S A 104:8149-8154.

Geisler C, Diba K, Pastalkova E, Mizuseki K, Royer S, Buzsáki G (2010) Temporal delays among place cells determine the frequency of population theta oscillations in the hippocampus. Proc Natl Acad Sci U S A 107:7957-7962.

Golomb D, Yue C, Yaari Y (2006) Contribution of persistent $\mathrm{Na}^{+}$current and $\mathrm{M}$-type $\mathrm{K}^{+}$current to somatic bursting in CAl pyramidal cells: combined experimental and modeling study. J Neurophysiol 96:1912-1926.

Gutfreund Y, Yarom Y, Segev I (1995) Subthreshold oscillations and resonant frequency in guinea-pig cortical neurons: physiology and modelling. J Physiol 483:621-640.

Hafting T, Fyhn M, Molden S, Moser MB, Moser EI (2005) Microstructure of a spatial map in the entorhinal cortex. Nature 436:801-806.

Halliwell JV, Adams PR (1982) Voltage-clamp analysis of muscarinic excitation in hippocampal neurons. Brain Res 250:71-92.

Harris KD, Henze DA, Hirase H, Leinekugel X, Dragoi G, Czurkó A, Buzsáki G (2002) Spike train dynamics predicts theta-related phase precession in hippocampal pyramidal cells. Nature 417:738-741.

Harvey CD, Collman F, Dombeck DA, Tank DW (2009) Intracellular dy- namics of hippocampal place cells during virtual navigation. Nature 461:941-946.

Hasselmo ME (2008) Grid cell mechanisms and function: contributions of entorhinal persistent spiking and phase resetting. Hippocampus 18:1213-1229.

Hasselmo ME, Eichenbaum H (2005) Hippocampal mechanisms for the context-dependent retrieval of episodes. Neural Netw 18:1172-1190.

Hoffman DA, Magee JC, Colbert CM, Johnston D (1997) $\mathrm{K}^{+}$channel regulation of signal propagation in dendrites of hippocampal pyramidal neurons. Nature 387:869-875.

Hopfield JJ (1995) Pattern recognition computation using action potential timing for stimulus representation. Nature 376:33-36.

Hu H, Vervaeke K, Storm JF (2002) Two forms of electrical resonance at theta frequencies, generated by M-current, h-current and persistent $\mathrm{Na}^{+}$current in rat hippocampal pyramidal cells. J Physiol 545:783-805.

Hu H, Vervaeke K, Storm JF (2007) M-channels (Kv7/KCNQ channels) that regulate synaptic integration, excitability, and spike pattern of CA1 pyramidal cells are located in the perisomatic region. J Neurosci 27:1853-1867.

Hu H, Vervaeke K, Graham LJ, Storm JF (2009) Complementary theta resonance filtering by two spatially segregated mechanisms in CA1 hippocampal pyramidal neurons. J Neurosci 29:14472-14483.

Hutcheon B, Yarom Y (2000) Resonance, oscillation and the intrinsic frequency preferences of neurons. Trends Neurosci 23:216-222.

Huxter J, Burgess N, O'Keefe J (2003) Independent rate and temporal coding in hippocampal pyramidal cells. Nature 425:828-832.

Jayet Bray LC, Quoy M, Harris FC, Goodman PH (2010) A circuit-level model of hippocampal place field dynamics modulated by entorhinal grid and suppression-generating cells. Front Neural Circuits 4:122.

Jensen O, Lisman JE (1996) Hippocampal CA3 region predicts memory sequences: accounting for the phase advance of place cells. Learn Mem 3:257-263.

Kamondi A, Acsády L, Wang XJ, Buzsáki G (1998) Theta oscillations in somata and dendrites of hippocampal pyramidal cells in vivo: activitydependent phase precession firing. Hippocampus 8:244-261.

Krnjević K (1993) Central cholinergic mechanisms and function. Prog Brain Res 98:285-292.

Lee MG, Chrobak JJ, Sik A, Wiley RG, Buzsáki G (1994) Hippocampal theta following selective lesion of the septal cholinergic system. Neuroscience 62:1033-1047.

Lengyel M, Szatmáry Z, Erdi P (2003) Dynamically detuned oscillations account for the coupled rate and temporal code of place cell firing. Hippocampus 13:700-714.

Leung LS (1984) Model of gradual phase shift of theta rhythm in the rat. J Neurophysiol 52:1051-1065.

Leung LS (1998) Generation of theta and gamma rhythms in the hippocampus. Neurosci Biobehav Rev 22:275-290.

Leung LS, Peloquin P (2006) $\mathrm{GABA}_{\mathrm{B}}$ receptors inhibit backpropagating dendritic spikes in hippocampal CA1 pyramidal cells in vivo. Hippocampus 16:388-407.

Leung LS, Peloquin P (2010) Cholinergic modulation differs between basal and apical dendritic excitation of hippocampal CA1 pyramidal cells. Cereb Cortex 20:1865-1877.

Leung LS, Yim CY (1986) Intracellular records of theta rhythm in hippocampal CAl cells of the rat. Brain Res 367:323-327.

Leung LS, Yim CY (1991) Intrinsic membrane potential oscillations in hippocampal neurons in vitro. Brain Res 553:261-274.

Leung LS, Yu HW (1998) Theta-frequency resonance in hippocampal CA1 neurons in vitro demonstrated by sinusoidal current injection. J Neurophysiol 79:1592-1596.

Losonczy A, Zemelman BV, Vaziri A, Magee JC (2010) Network mechanisms of theta related neuronal activity in hippocampal CA1 pyramidal neurons. Nat Neurosci 13:967-972.

Magee JC (1998) Dendritic hyperpolarization-activated currents modify the integrative properties of hippocampal CAl pyramidal neurons. J Neurosci 18:7613-7624

Magee JC (2001) Dendritic mechanisms of phase precession in hippocampal CA1 pyramidal neurons. J Neurophysiol 86:528-532.

Magistretti J, Alonso A (1999) Biophysical properties and slow voltage dependent inactivation of a sustained sodium current in entorhinal cortex layer-II principal cells: a whole-cell and single-channel study. J Gen Physiol 114:491-509.

McLelland D, Paulsen O (2009) Neuronal oscillations and the rate-to-phase 
transform: mechanism, model and mutual information. J Physiol 587:769-785.

Mehta MR, Lee AK, Wilson MA (2002) Role of experience and oscillations in transforming a rate code into a temporal code. Nature 417:741-746.

Moser EI, Kropff E, Moser MB (2008) Place cells, grid cells, and the brain's spatial representation system. Annu Rev Neurosci 31:69-89.

Muller R (1996) A quarter of a century of place cells. Neuron 17:813-822.

Nolan MF, Malleret G, Dudman JT, Buhl DL, Santoro B, Gibbs E, Vronskaya S, Buzsáki G, Siegelbaum SA, Kandel ER, Morozov A (2004) A behavioral role for dendritic integration: HCN1 channels constrain spatial memory and plasticity at inputs to distal dendrites of CA1 pyramidal neurons. Cell 119:719-732.

O'Keefe J, Nadel L (1978) The hippocampus as a cognitive map. London: Oxford UP.

O'Keefe J, Recce ML (1993) Phase relationship between hippocampal place units and the EEG theta rhythm. Hippocampus 3:317-330.

Prescott SA, Sejnowski TJ (2008) Spike-rate coding and spike-time coding are affected oppositely by different adaptation mechanisms. J Neurosci 28:13649-13661.

Rall W (1964) Theoretical significance of dendritic trees for neuronal inputoutput relations. In: Neural theory and modeling (Reiss RF, ed), pp 7397. Stanford, CA: Stanford UP.

Romani S, Sejnowski TJ, Tsodyks M (2011) Intracellular dynamics of virtual place cells. Neural Comput 23:651-655.

Schmidt R, Diba K, Leibold C, Schmitz D, Buzsáki G, Kempter R (2009) Singletrial phase precession in the hippocampus. J Neurosci 29:13232-13241.

Skaggs WE, McNaughton BL, Wilson MA, Barnes CA (1996) Theta phase precession in hippocampal neuronal populations and the compression of temporal sequences. Hippocampus 6:149-172.

Stewart M, Fox SE (1990) Do septal neurons pace the hippocampal theta rhythm? Trends Neurosci 13:163-168.
Tsodyks MV, Skaggs WE, Sejnowski TJ, McNaughton BL (1996) Population dynamics and theta rhythm phase precession of hippocampal place cell firing: a spiking neuron model. Hippocampus 6:271-280.

Vanderwolf CH (1988) Cerebral activity and behavior: control by cholinergic and serotonergic systems. Int Rev Neurobiol 30:225-340.

Vervaeke K, Hu H, Graham LJ, Storm JF (2006) Contrasting effects of the persistent $\mathrm{Na}^{+}$current on neuronal excitability and spike timing. Neuron 49:257-270.

Wallenstein GV, Hasselmo ME (1997) GABAergic modulation of hippocampal population activity: sequence learning, place field development, and the phase precession effect. J Neurophysiol 78: 393-408.

Wang HS, Pan Z, Shi W, Brown BS, Wymore RS, Cohen IS, Dixon JE, McKinnon D (1998) KCNQ2 and KCNQ3 potassium channel subunits: molecular correlates of the M-channel. Science 282:1890-1893.

White JA, Budde T, Kay AR (1995) A bifurcation analysis of neuronal subthreshold oscillations. Biophys J 69:1203-1217.

Witter MP (2007) The perforant path: projections from the entorhinal cortex to the dentate gyrus. Prog Brain Res 163:43-61.

Yamada WM, Kerr C, Adams PR (1989) Multiple channels and calcium dynamics. In: Methods in neuronal modeling (Segev I, Koch C, eds), pp 97-133. Cambridge, MA: MIT.

Ylinen A, Soltész I, Bragin A, Penttonen M, Sik A, Buzsáki G (1995) Intracellular correlates of hippocampal theta rhythm in identified pyramidal cells, granule cells, and basket cells. Hippocampus 5:78-90.

Yue C, Remy S, Su H, Beck H, Yaari Y (2005) Proximal persistent $\mathrm{Na}^{+}$ channels drive spike afterdepolarizations and associated bursting in adult CA1 pyramidal cells. J Neurosci 25:9704-9720.

Zugaro MB, Monconduit L, Buzsáki G (2005) Spike phase precession persists after transient intrahippocampal perturbation. Nat Neurosci 8:67-71. 